\title{
CST SUSPENSION ANALYSIS FOR SLURRY PUMPS OF TANK 40
}

Si Young Lee and Richard A. Dimenna

Westinghouse Savannah River Company

Savannah River Site

Aiken, SC 29808

Prepared for the U.S. Department of Energy Under Contract Number DEAC09-96SR18500

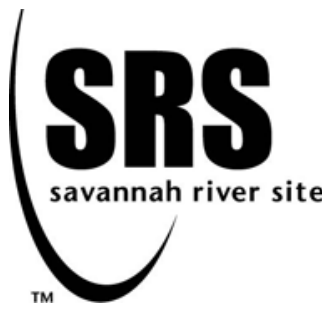


This document was prepared in conjunction with work accomplished under Contract No. DE-AC09-96SR18500 with the U. S. Department of Energy.

\section{DISCLAIMER}

This report was prepared as an account of work sponsored by an agency of the United States Government. Neither the United States Government nor any agency thereof, nor any of their employees, makes any warranty, express or implied, or assumes any legal liability or responsibility for the accuracy, completeness, or usefulness of any information, apparatus, product or process disclosed, or represents that its use would not infringe privately owned rights. Reference herein to any specific commercial product, process or service by trade name, trademark, manufacturer, or otherwise does not necessarily constitute or imply its endorsement, recommendation, or favoring by the United States Government or any agency thereof. The views and opinions of authors expressed herein do not necessarily state or reflect those of the United States Government or any agency thereof.

This report has been reproduced directly from the best available copy.

Available for sale to the public, in paper, from: U.S. Department of Commerce, National Technical Information Service, 5285 Port Royal Road, Springfield, VA 22161, phone: (800) 553-6847, fax: (703) 605-6900

email: orders@ntis.fedworld.gov

online ordering: http://www.ntis.gov/help/index.asp

Available electronically at http://www.osti.gov/bridge

Available for a processing fee to U.S. Department of Energy and its contractors, in paper, from: U.S. Department of Energy, Office of Scientific and Technical Information, P.O. Box 62, Oak Ridge, TN 37831-0062,

phone: (865)576-8401,

fax: (865)576-5728

email: $\underline{\text { reports@ adonis.osti.gov }}$ 
WSRC-TR-2004-00207

KEYWORDS:

Tank Flow Model Numerical Approach CST Suspension Model CST Settling Estimation CFD Approach for Flow Patterns

RETENTION - Permanent

\section{CST Suspension Analysis for Slurry Pumps of Tank 40}

SAVANNAH RIVER TECHNOLOGY CENTER

Si Young Lee and Richard A. Dimenna

March 2004

Westinghouse Savannah River Company

Savannah River Site

Aiken, SC 29808

Prepared for the U.S. Department of Energy Under Contract Number DEAC09-96SR18500

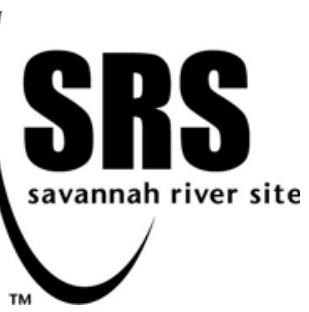


WSRC-TR-20043-00207

(This Page Intentionally Left Blank) 
This page was intentionally left blank 
WSRC-TR-2004-00207

(This Page Intentionally Left Blank) 


\section{Table of Contents}

Acknowledgements $\quad$ vi

List of Figures vii

List of Tables $\quad$ ix

Nomenclature $\quad$ xi

$\begin{array}{ll}\text { Abstract } & 1\end{array}$

1 Introduction 3

2 Modeling Approach and Analysis $\quad 7$

2.1 Flow Criterion for CST Suspension............................................................... 7

2.2 Settling Velocity for Mono-sized Particles in Stagnant Fluid ................................ 12

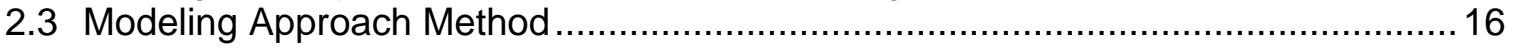

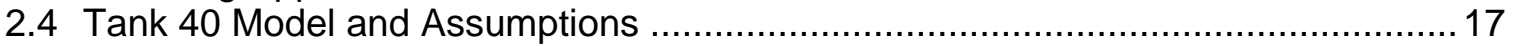

3 Results and Discussions 21

4 Summary and Conclusions $\quad 45$

5 References $\quad 47$ 
WSRC-TR-2004-00207

(This Page Intentionally Left Blank) 
WSRC-TR-2004-00207

\section{List of Figures}

Figure1. Schematic of Tank 40 layout with major flow obstructions of support columns and four slurry mixing pumps (Each component not scaled properly) .................... 4

Figure 2. Typical flow dissipation and evolution of a turbulent jet flow along the discharge direction

Figure 3. Schematic representation of solid concentration and velocity distributions for various flow regimes of solids-laden slurry $\left(\mathrm{V}_{\mathrm{c}}\right.$ is a minimum velocity or scouring velocity to initiate the movement of particle from the deposit area.)......................10

Figure 4. CST suspension velocity as function of particle sizes for different tank levels .....11

Figure 5. CST settling velocities as function of particle sizes for different solid contents in tank fluid using Oliver's correlation of Table 3

Figure 6. Three-dimensional modeling boundary for the present analysis of the Tank 40 facility with four slurry pumps

Figure 7. Three-dimensional computational domain as modeled for the present analysis .. 20

Figure 8. Hexahedral meshes on the $x-y$ computational domain for a three-dimensional CFD model of Tank 40 with four mixing pumps.

Figure 9. Turbulence intensity distributions at the discharge plane of the pump in Tank 40 showing the red region indicates the flow fluctuation larger than $30 \%$ of local average velocity magnitude

Figure 10. Velocity magnitude distributions along the principal discharge direction of pump $\mathrm{G}$ in Tank 40

Figure 11. CST suspension zones at the discharge plane of the pump in Tank 40 showing the red region has the velocity magnitude larger than minimum velocity required to suspend 700 micron CST particle

Figure 12. CST suspension zones at the vertical plane crossing two pumps, pump G and pump $\mathrm{H}$, in Tank 40 showing the red region has the velocity magnitude larger than minimum velocity required to suspend 700 micron CST particle

Figure 13. Flow circulation patterns for the best aiming directions to maximize suspension region of CST particles with four pumps operated in indexed nozzle positions

Figure 14. Turbulence intensity distributions at the discharge plane of the pump in Tank 40 showing the red region indicates the flow fluctuation larger than $30 \%$ of local average velocity magnitude.....

Figure 15. Flow circulation patterns and fluid rotations driven by slurry pumps for the best aiming directions of four slurry pumps under the indexed pump operations .. 29

Figure 16. Flow circulations at the discharge plane for the best aiming directions of four slurry pumps under the indexed pump operations showing that red zone has higher velocity required to suspend the 700 micron CST particles

Figure 17. Flow circulations for four pump operations at the vertical plane crossing the two pumps, pump $\mathrm{G}$ and pump $\mathrm{H}$, for the best aiming directions of four slurry pumps under the indexed pump operations showing that red zone has higher velocity required to suspend the 700 micron CST particles

Figure 18. Comparison of quasi-steady flow patterns between stationary indexed operations and rotational mode operations of one slurry pump (pumps $G$ ) in Tank 40 showing that the red zone indicates the suspension zone of 700 micron CST. 
Figure 19. Comparison of quasi-steady flow patterns between stationary indexed operations and rotational mode operations of two slurry pumps (pumps $G$ and $\mathrm{H}$ ) in Tank 40 showing that the red zone indicates the suspension zone of 700 micron CST

Figure 20. Quantitative comparison of velocity magnitudes along the principal discharge flow direction (line B-B') of pump $G$ for indexed and rotational pump operations under two pump operations of pump $\mathrm{G}$ and $\mathrm{H}$

Figure 21. Comparison of quasi-steady flow patterns between stationary indexed operations and rotational mode operations of four slurry pumps (pumps B2, B6, $\mathrm{G}$, and $\mathrm{H}$ ) in Tank 40

Figure 22. Comparison of quasi-steady flow patterns between stationary indexed operations and rotational mode operations of four slurry pumps (pumps B2, B6, $\mathrm{G}$, and $\mathrm{H}$ ) in Tank 40

Figure 23. Comparison of quasi-steady fluid rotations between stationary indexed operations and rotational mode operations of four slurry pumps (pumps B2, B6, $\mathrm{G}$, and $\mathrm{H}$ ) in Tank 40 showing that the red zone indicates the suspension zone of 700 micron CST

Figure 24. Comparison of quasi-steady flow patterns between stationary indexed operations and rotational mode operations of four slurry pumps (pumps B2, B6, $\mathrm{G}$, and $\mathrm{H}$ ) in Tank 40 showing that the red zone indicates the suspension zone of 700 micron CST

Figure 25. Transient flow velocity distributions along the centerline A-B of the tank at the elevation of the pump discharge nozzle for rotational operation of one slurry pump (pumps $\mathrm{G}$ ) in Tank 40 showing that transient time to reach steady state is about 180 seconds

Figure 26. Transient flow patterns for one pump run with $1 / 3 \mathrm{rpm}$ rotational speed showing that the red zone indicates the suspension zone of 700 micron CST...... 36

Figure 27. Quasi-steady flow patterns for one pump run with $1 / 3 \mathrm{rpm}$ rotational speed showing that the red zone indicates the suspension zone of 700 micron CST...... 37

Figure 28. Transient velocity distributions for one pump run with $1 / 3 \mathrm{rpm}$ rotational speed along the centerline A-B crossing the central column of Tank 40.

Figure 29. Quasi-steady flow patterns for two pump runs with $1 / 3 \mathrm{rpm}$ rotational speed showing that the red zone indicates the suspension zone of 700 micron CST...... 39

Figure 30. Transient velocity distributions along the centerline line A-B of tank rotational operations of two pumps (pump $\mathrm{G}$ and $\mathrm{H}$ )

Figure 31. Quasi-steady flow patterns for four pump runs with $1 / 3 \mathrm{rpm}$ rotational speed showing that the red zone indicates the suspension zone of 700 micron CST..... 41

Figure 32. Transient velocity distributions for four pump run with $1 / 3 \mathrm{rpm}$ rotational speed along the centerline A-B crossing the central column of Tank 40.

Figure 33. Velocity distributions for four pump run with $1 / 3 \mathrm{rpm}$ rotational speed for the nozzle discharge plane and the vertical central plane crossing the central column of Tank 40 showing that the red zone indicates the suspension zone of 400 micron CST particles 
WSRC-TR-2004-000207

\section{List of Tables}

Table 1. Reference design and operating conditions of Tank 40 used for the present analysis......

Table 2. Minimum velocities of particle suspension and transport/removal for the various particle sizes in fluid density $1.252 \mathrm{gm} / \mathrm{cc}$ (particle density=2.66 gm/cc)

Table 3. Literature correlations for relative settling velocities based on solid volume fraction as stated in Ref. 4 (relative settling velocity $V_{r}$ is defined by eq. (12))......15

Table 4. Comparison of quasi-steady suspension distance of 700-micron CST particle between stationary indexed operations and rotational mode operations of two slurry pumps (pumps $\mathrm{G}$ and $\mathrm{H}$ ) in Tank 40 .....

Table 5. Comparison of settling times of 700-micron CST particle between maximum settling time allowable during various numbers of pump operations and free settling velocity of quiescent fluid medium in Tank 40 . 
WSRC-TR-2004-00207

(This Page Intentionally Left Blank) 


\section{Abstract}

Computational fluid dynamics methods were used to develop and provide a slurry pump operating guidance for CST mixing and suspension in Tank 40. Flow patterns calculated by the model were used to evaluate the performance of various combinations of operating pumps. The models focused on suspension of the CST particles to avoid settling during pump operations using the four existing slurry pumps. The models and calculations were based on prototypic tank geometry and expected normal operating conditions as defined by the Salt Engineering customer.

Computational fluid dynamics models of Tank 40 with different operating conditions were developed using the FLUENT ${ }^{T M}$ code. The modeling results were used to assess the efficiency of CST suspension and mixing operations in the 85-ft tank. The models employed a three-dimensional approach, a two-equation turbulence model, and an approximate representation of flow obstructions. The calculated local velocity magnitude was used as a measure of CST suspension and mixing capability.

For the simulations, a series of the modeling calculations was performed with indexed pump orientations and pump rotation until an efficient flow pattern over the entire domain of tank fluid was established for CST suspension. The calculated results demonstrated that the existing slurry pump running at $7600 \mathrm{gpm}$ flowrate and $1 / 3 \mathrm{rpm}$ rotating pump speed could suspend the CST particles from the tank with a 200 in liquid level, based on a minimum suspension velocity of about $1.1 \mathrm{ft} / \mathrm{sec}$ for 700 micron CST particles.

The results showed that the suspension distance for rotating pumps is smaller than that for indexed pump operations for similar operating conditions. However, the suspension extent for the two cases has about the same total area. Further results showed that the capabilities of CST suspension were affected by the number of operating pumps and pump rotating speed. 
Report: WSRC-TR-2004-00207

Date: $\quad 6 / 14 / 2004$

Page: $\quad 2$ of 48
WESTINGHOUSE SAVANNAH RIVER COMPANY

CST SUSPENSION ANALYSIS FOR SLURRY PUMPS OF TANK 40

(This Page Intentionally Left Blank) 


\section{Introduction}

Tank 40 is a 85-ft diameter, flat-bottomed, cylindrical carbon steel tank with $6.75 \mathrm{ft}$ diameter central support column. Its contents consist of slurry fluid and crystalline silicotitanate (CST) particles. The slurry is primarily a mixture of aqueous fluids with smaller concentrations of cesium. It sounds more like a solution than a slurry. The CST is settled near the bottom of the tank, and it will then be hydraulically mobilized and suspended by submersible mixer pumps and transferred to other tanks. The CST material in the tank is being used as an inorganic ion-exchange medium to remove cesium from the high-level radioactive waste tanks at the Savannah River Site (SRS). Sorption of the cesium from the slurry mixture results in concentrating the cesium into the volume of the CST.

Tank 40 has four slurry pumps manufactured by the Lawrence Company [1] available for CST suspension operations. Each pump has a suction inlet at the bottom and two opposing discharge nozzles, 3.625 in diameter. The pump is normally submerged to approximately the level of 12.375 inches off the bottom as shown in Fig. 1, allowing a recirculating mixture of CST and fluid to serve as the feed flow. The nozzle elevation corresponds to about 4.875 inches from the tank floor to the bottom of the pump suction screen. All pumps are located at a 29 -ft radial distance from the tank center as shown schematically in Fig. 1. Detailed locations of all four pumps are also shown in the figure [2]. Each pump can rotate at $1 / 3 \mathrm{rpm}$ using a variable frequency drive. The flow pattern generated on the tank bottom defines the suspension distance from the pump nozzle exit to the point with its local velocity magnitude corresponding to minimum CST suspension velocity when the pump is operated. This distance is used as one of the measures or indicators of the CST mixing or suspension ability of a pump. After the mixer suspends the CST particles, waste transfers from Tank 40 to another tank will be performed.

The primary objective of the present work is to calculate the flow circulation patterns for CST suspension in Tank 40 under various combinations of number of operating pumps and their nozzle discharge orientation. The flow patterns calculated by the model will be used to evaluate the mixing capabilities of the slurry mixers. Figure 2 shows the typical flow development and evolution of a jet flow discharged by a slurry mixer obtained from previous modeling results $[4,5]$ and literature information [11].

The analysis results will be used to evaluate hydraulic suspension capabilities for CST mixing. This information will also assist in the operating plan for the Tank 40 cesium removal and in identifying special operation requirements for the suspension of the tank CST materials. 


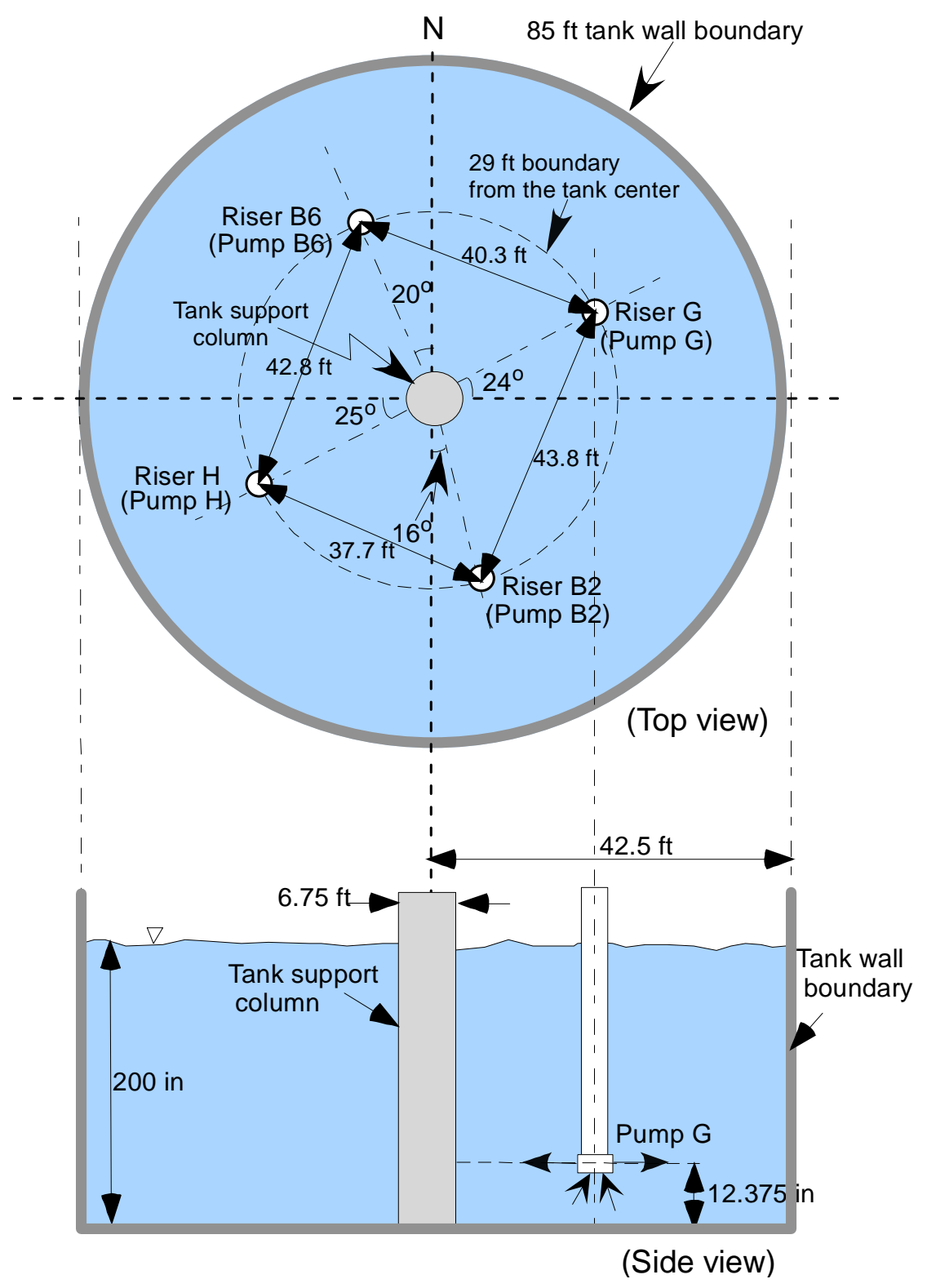

(Ref. Drawing [2]: W700759)

Figure 1. Schematic of Tank 40 layout with major flow obstructions of support columns and four slurry mixing pumps (Each component not scaled properly). 
Table 1. Reference design and operating conditions of Tank 40 used for the present analysis.

\begin{tabular}{|c|c|}
\hline Physical parameters & Parameter values \\
\hline Particle density & $2.66 \mathrm{gm} / \mathrm{cc}$ \\
\hline $\begin{array}{c}\text { CST particle size } \\
\text { (as received) }\end{array}$ & $\begin{array}{c}250 \text { to } 700 \text { microns } \\
\text { (avg. about } 400 \text { microns) }\end{array}$ \\
\hline $\begin{array}{c}\text { Max. CST particle size } \\
\text { (crushed) }\end{array}$ & 177 microns \\
\hline Max. number of pumps available & 4 \\
\hline Pump flowrate & $3800 \mathrm{gpm} / \mathrm{nozzle}$ \\
\hline Number of nozzles each pump & 2 \\
\hline Flow velocity at pump discharge inlet & $118.1 \mathrm{ft} / \mathrm{sec}$ (corresponding to 3800 \\
gpm in 3.625-in nozzle)
\end{tabular}

Note:* 700 micron (maximum CST size) will be used for one of the reference conditions. 


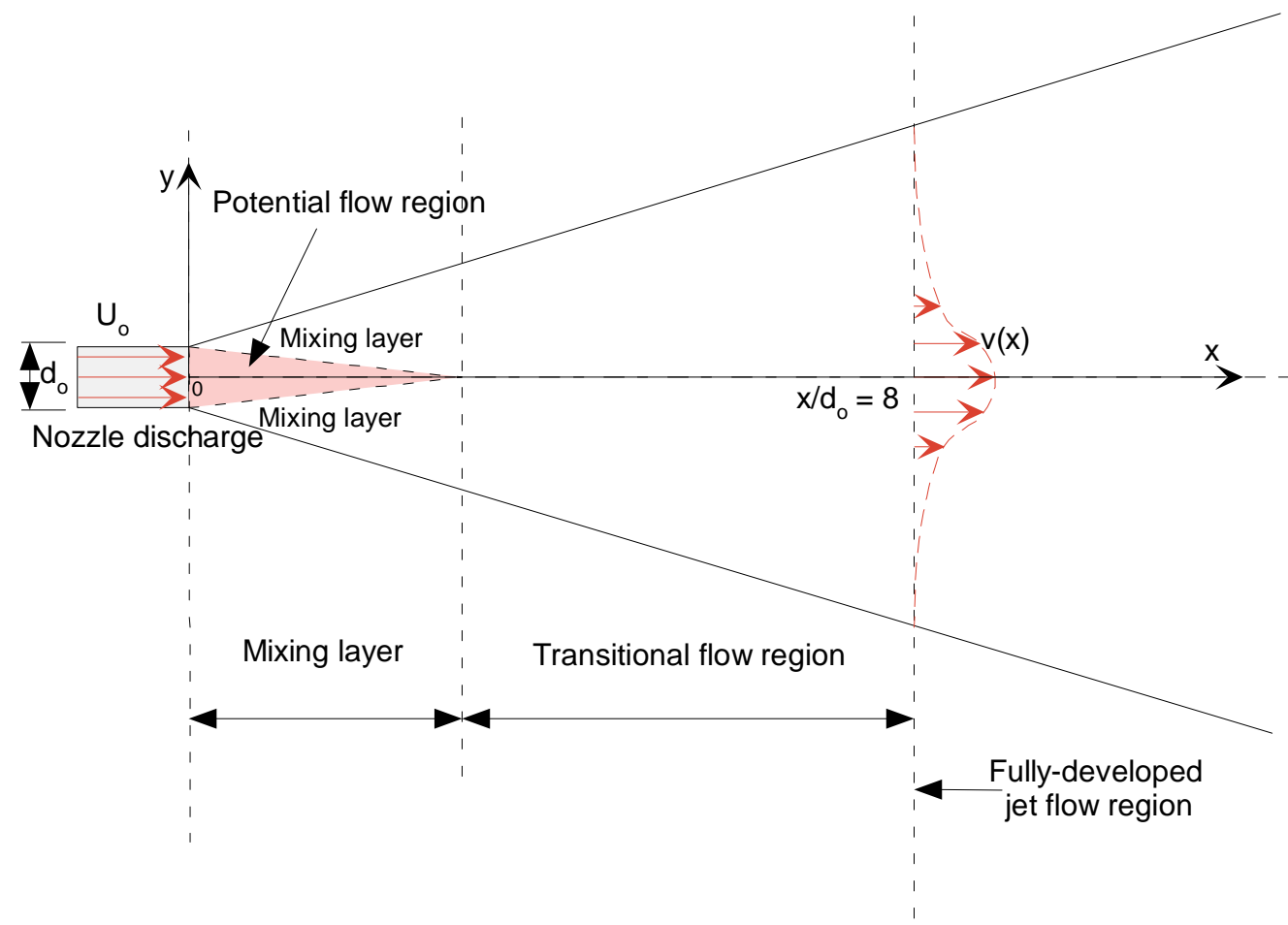

(Two-dimensional jet flow at the discharge plane)

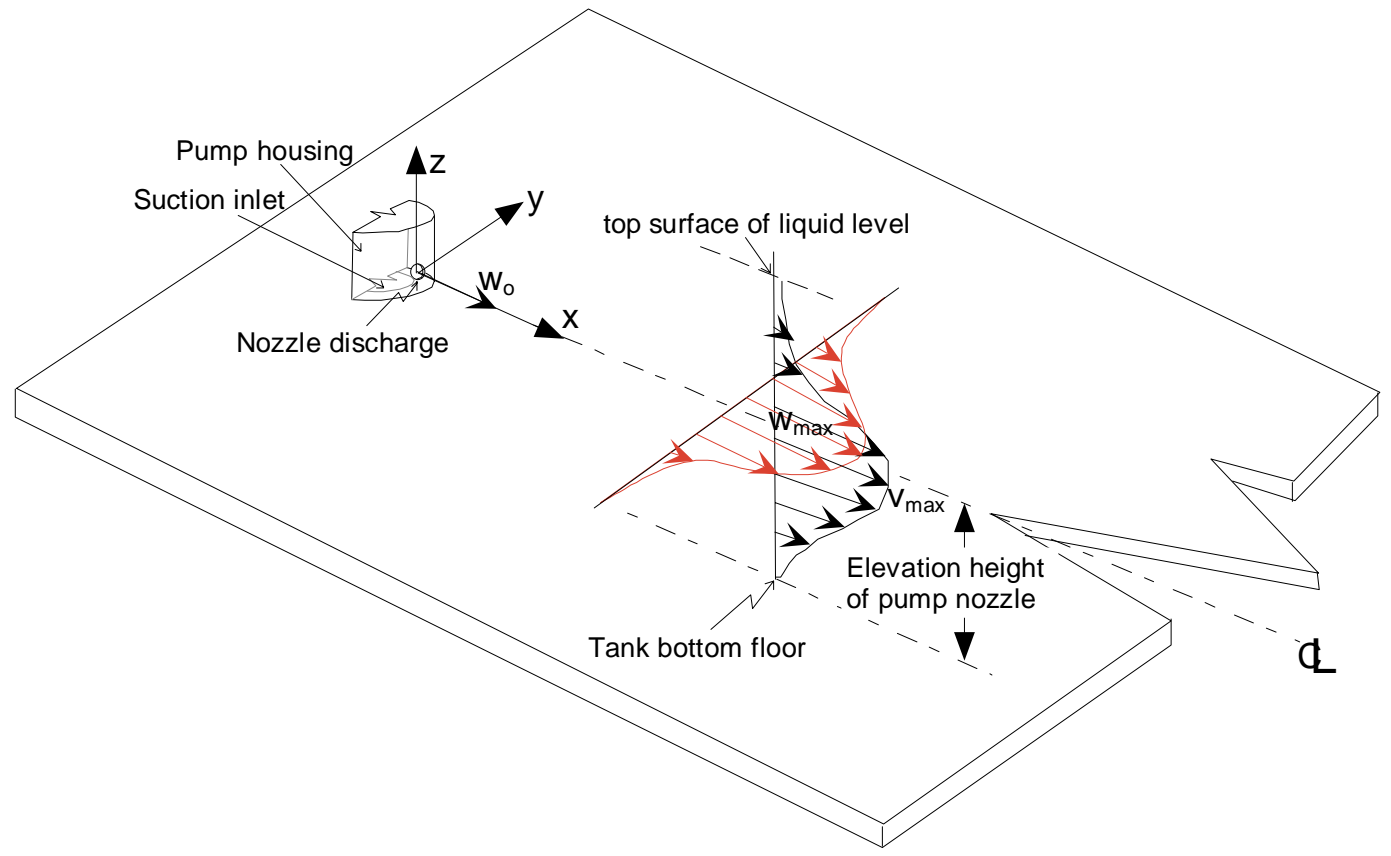

(Three-dimensional jet flow near the tank wall)

Figure 2. Typical flow dissipation and evolution of a turbulent jet flow along the discharge direction 


\section{Modeling Approach and Analysis}

A three-dimensional CFD approach is used to calculate flow patterns for the CST suspension operations of Tank 40 and to evaluate optimum operating conditions for CST mixing in the tank. A finite volume CFD code, FLUENT [9], is used here to perform the Tank 40 modeling and analysis. A prototypic geometry is modeled with a non-uniform, non-orthogonal, and hexahedral mesh.

The decay rate of the jet axial velocity and the evolution of flow patterns are potentially important phenomena affecting solid suspension and mixing operations. They result from the interaction of the submerged turbulent jet with the tank wall, internal solid obstructions, and free surface. The ability to shear the settled particle layer is also directly related to the local velocity. Hence, local flow velocity magnitude generated by the pump discharge jet is considered one of the key parameters governing the degree of CST solid suspension and turbulent mixing in the present work.

The present models consider flow obstructions such as key pump support structures and central support column.

\subsection{Flow Criterion for CST Suspension}

To establish the flow criterion for a quantitative estimation of CST suspension, decay characteristics of a submerged jet flow and assessment of the slurry flow regime need to be discussed briefly using literature information and our previous analyses. When a turbulent jet of fluid is discharged from a nozzle with a diameter $d_{0}$, it both entrains fluid and expands as shown in Fig. $2[6,7,10,13]$. Most mixing action and entrainment takes place in the region of fully-developed flow which begins at a distance of approximately eight nozzle diameters from the discharge plane. The non-dimensional velocity distribution $\varphi_{v}$ along the jet axis of this region for a homogeneous fluid jet is given by [13]

$\varphi_{v}=\left(\frac{v(x)}{U_{o}}\right)=C_{o}\left[\frac{x}{d_{o}}\right]^{-1}=C_{o} \eta^{-1}$

In eq. (1), $C_{o}$ is a constant determined by the turbulence characteristics of the jet, $U_{o}$ the nozzle exit velocity, $v(x)$ the local velocity at a point $x$, and $x$ the distance from nozzle. Abramovich (1963) correlated the experimental data for a free turbulent jet submerged in fluid using the non-dimensional form provided by eq. (1). From his work, the proportional constant $C_{o}$ in eq. (1) was determined to be 6.3158 .

Equation (1) shows that the velocity at any point in the region of established flow is directly proportional to the product, $d_{o} U_{0}$. Thus, the one-dimensional entraining distance corresponding to the minimum entrainment velocity can be estimated theoretically when nozzle size and pumping flowrate are provided.

However, the fluid region for the present work has both a solid boundary and a free surface boundary as the jet expands into the downstream region and then the flow recirculates in the tank. The spreading fluid is retarded by the frictional resistance of the wall. The inner part of the flow may be expected to show a certain structural similarity to a boundary layer, whereas entrainment of quiescent fluid occurs near the outer edge of the flow, which accordingly is likely to resemble a free jet in character. 
When a solid structure or wall surface is present near the jet nozzle, the jet flow will feel a three-dimensional interaction from both the wall boundary and the free surface. The literature [8] has shown that the flow region of the jet up to 40 nozzle diameters, $\eta=40$ in eq. (1), is not affected by the presence or absence of a wall near the nozzle assuming the jet does not contact the wall in that distance.

Average flow velocity, particle size and density, and slurry flow regime are key important parameters in determining the transport patterns of particles in a slurry [16], which are closely related to the solid resuspension. In this case, the critical velocity is defined as the minimum velocity that can initiate the movement of the solids deposited near the bottom of the tank. Graf [16] correlated the critical velocity $V_{c}$ empirically in terms of geometrical dimensions and the ratio of particle to fluid densities using data available in the literature.

$V_{c}=\left(\frac{d}{H}\right)^{-0.1} \sqrt{2.5 g d\left(\frac{\rho_{s}}{\rho_{f}}-1\right)}$

In eq. (2) $d$ and $H$ are the particle diameter and tank liquid level, respectively. As seen in Fig. 3 , when the average flow velocity is much larger than the critical velocity, $V_{c}$, the literature results show that solid particles in a continuous flow field are homogeneously distributed [16]. When the flow velocity required for CST transport and suspension is exceeded, the solid-laden flow can be treated as a homogeneous fluid. Thus, once solid particles are suspended by the continuous-phase flow, the conditions of the first of the three typical slurry flow fields shown in Fig. 3 are satisfied. The present flow calculations are based on a homogeneous single-phase fluid flow. Table 2 shows minimum suspension velocities of particles for three different mono-sized particle systems with 2.7 specific gravity (spg) particle and $1.26 \mathrm{spg}$ fluid. The flow criterion required for CST suspension will be used in the analysis as shown in Table 2. 
Table 2. Minimum velocities of particle suspension and transport/removal for the various particle sizes in fluid density $1.252 \mathrm{gm} / \mathrm{cc}$ (particle density=2.66 gm/cc)

\begin{tabular}{|c|c|c|}
\hline $\begin{array}{c}\text { Tank level } \\
\text { (inches) }\end{array}$ & $\begin{array}{c}\text { CST particle size } \\
\text { (microns) }\end{array}$ & $\begin{array}{c}\text { Min. velocity }\left(V_{c}\right) \text { required to suspend particle deposited } \\
\text { from horizontal wall surface computed by eq. (2) } \\
{[\mathrm{m} / \mathrm{sec}](\mathrm{ft} / \mathrm{sec})}\end{array}$ \\
\hline \multirow{3}{*}{$200^{*}$} & 177 & {$[0.195](0.640)$} \\
\cline { 2 - 3 } & 400 & {$[0.270](0.887)$} \\
\cline { 2 - 3 } & $700^{\star}$ & {$[0.338](1.110)^{\star}$} \\
\hline \multirow{3}{*}{180} & 177 & {$[0.193](0.633)$} \\
\cline { 2 - 3 } & 400 & {$[0.267](0.877)$} \\
\cline { 2 - 3 } & 700 & {$[0.334](1.097)$} \\
\hline
\end{tabular}

Note:* The present modeling calculations will use these values as the nominal reference conditions. 


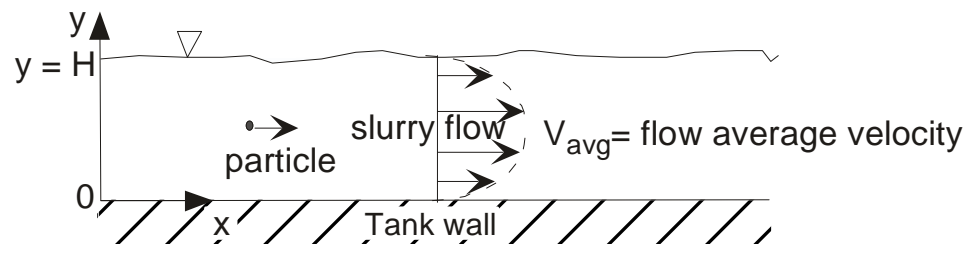

Case a: For homogeneous flow regime $\left(\mathrm{V}_{\mathrm{avg}} \gg>\mathrm{V}_{\mathrm{c}}\right.$ : the present case $)$

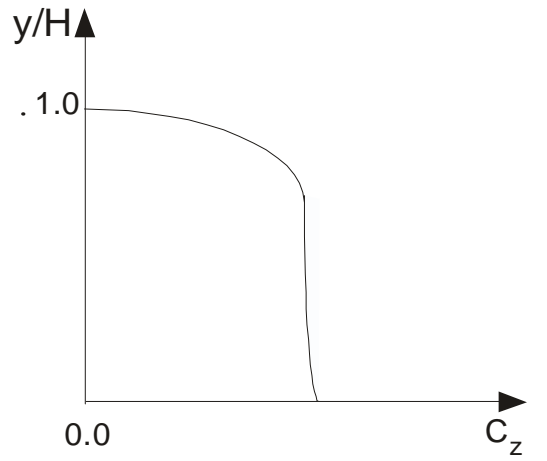

(Solid concentration distribution)

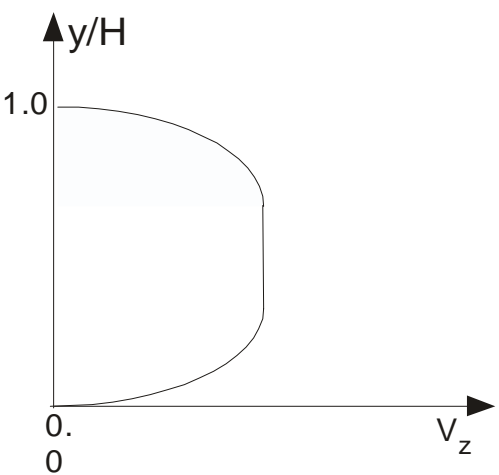

(Flow velocity distribution)

Case b: For non-homogeneous flow regime $\left(\mathrm{V}_{\mathrm{avg}} \sim \mathrm{V}_{\mathrm{C}}\right)$

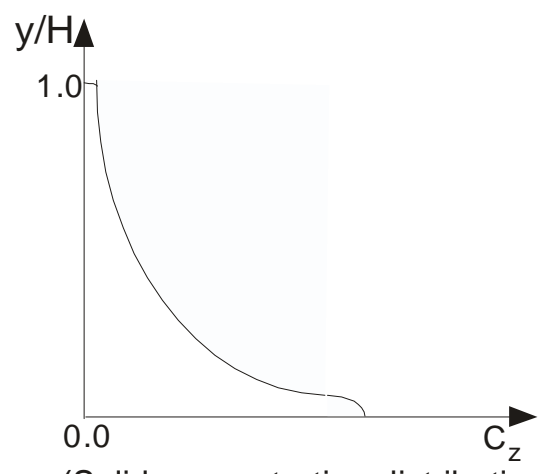

(Solid concentration distribution)

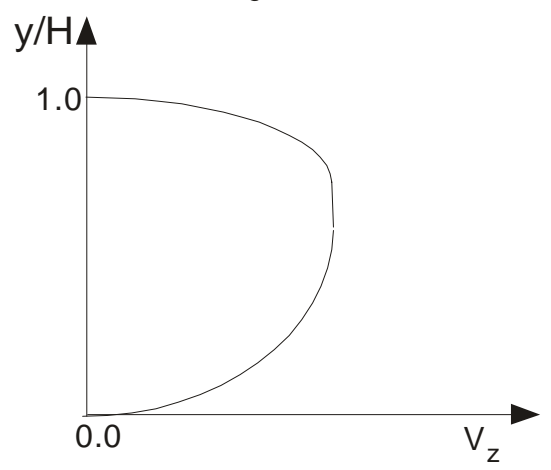

(Flow velocity distribution)

Case c: For non-homogeneous flow regime with solid particle deposit $\left(\mathrm{V}_{\mathrm{avg}}<\mathrm{V}_{\mathrm{C}}\right)$

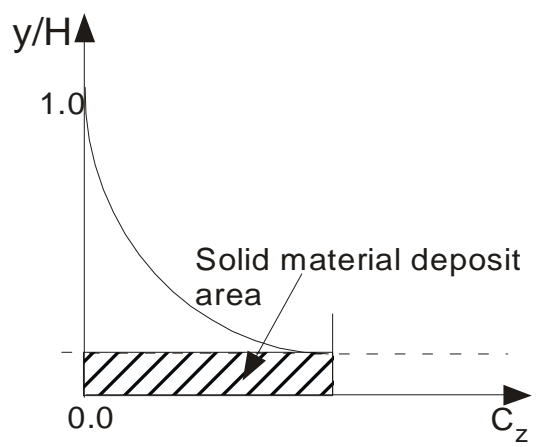

(Solid concentration distribution)

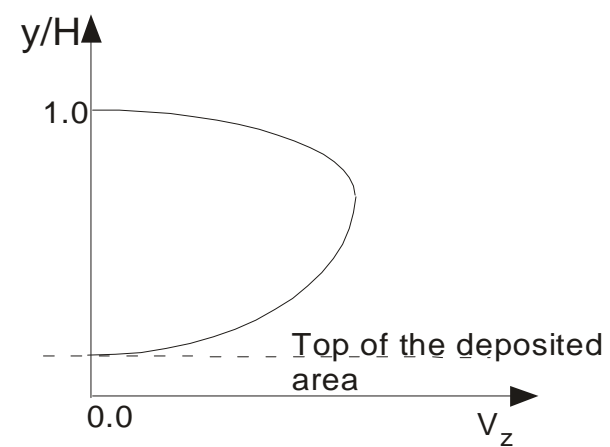

(Flow velocity distribution)

Figure 3. Schematic representation of solid concentration and velocity distributions for various flow regimes of solids-laden slurry $\left(V_{c}\right.$ is a minimum velocity or scouring velocity to initiate the movement of particle from the deposit area.) 
The flow patterns calculated in the Tank 40 modeling analysis are used to estimate the effectiveness of CST suspension operations in terms of local velocity magnitude and to interpret the mixing performance calculations for Tank 40 using the minimum required velocity presented in Table 2 .

It is important to recognize that the minimum suspension velocity determined by the empirical correlation is not a precise measure. It is dependent on the material characteristics, particle shape, and packing types of the CST layer settled on the tank floor, but it is also affected by the uncertainty in evaluating the suspension zones of the CST materials in the tank. Previous analysis [7] demonstrates reasonable agreement between the literature information and the present velocity criterion used for the suspension and mixing operations of solid particles in tank. Thus, local fluid velocity at any distance from the pump nozzle is employed as a measure of the slurrying and suspension efficiency of the CST particle in Tank 40. For the present analysis, local fluid velocity at any distance from the pump nozzle is compared to the flow criterion of $1.1 \mathrm{ft} / \mathrm{sec}$ as a measure or indicator for 700-micron CST suspension in Tank 40 for conservative estimation since the largest CST size as received in the tank is about 700 microns.

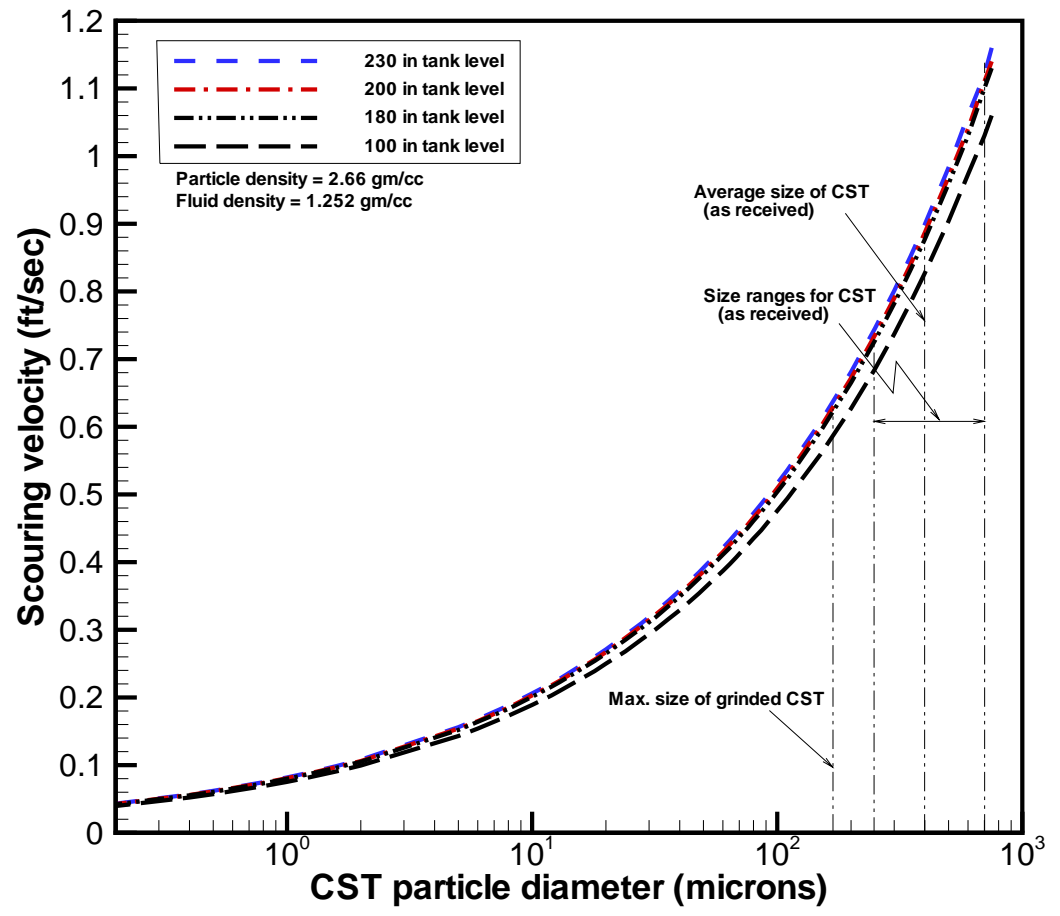

Figure 4. CST suspension velocity as function of particle sizes for different tank levels 


\subsection{Settling Velocity for Mono-sized Particles in Stagnant Fluid}

The drag force on an isolated solid particle moving in an infinite expanse stagnant fluid is represented by the equation,

$$
F_{D}=\frac{1}{2} C_{D} \rho_{f} v_{f}^{2} A_{p}
$$

In eq. (3) $\rho_{f}$ is density of fluid. $A_{p}$ represents the projected cross-sectional area of the particle perpendicular to the direction of motion. $C_{D}$ is the drag coefficient at the surface of particle when a solid particle is falling downward with velocity $v_{f}$. The drag coefficient $C_{D}$ is dependent on particle shape and flow regime in terms of Reynolds number $(R e)$.

For the case of free particles of spheres with a density of $\rho_{p}$ and without interaction or hindering effects due to the presence of other particles, the drag force $F_{D}$ equals the force of gravity $F_{G}$, including the buoyancy force of the particle with solid volume $V_{p}$ submerged in a quiescent fluid.

$$
\begin{aligned}
F_{G} & =V_{p}\left(\rho_{p}-\rho_{f}\right) g \\
& =F_{D}
\end{aligned}
$$

After some algebraic manipulations, eqs. (3) and (4) become

$$
v_{f}=\left[\left(\frac{2}{C_{D}}\right)\left(\frac{V_{p}}{A_{p}}\right) g \frac{\left(\rho_{p}-\rho_{f}\right)}{\rho_{f}}\right]^{0.5}=\left[\left(\frac{2}{C_{D}}\right) \varphi g \frac{\left(\rho_{p}-\rho_{f}\right)}{\rho_{f}}\right]^{0.5}
$$

When the particle has a spherical shape with diameter $d_{p}$, the ratio $(\varphi)$ of the particle volume to its projected area in eq. (5) is $(2 / 3) d_{p}$. That is,

$v_{f}=\left[\left(\frac{4}{3 C_{D}}\right) d_{p} g \frac{\left(\rho_{p}-\rho_{f}\right)}{\rho_{f}}\right]^{0.5}$

In this situation, the flow is assumed to be slow viscous or Stokes's flow. In 1850, Stokes derived the solution for viscous flow past a sphere at small values of the Reynolds number by using the momentum equation without inertia terms in a spherical polar coordinate system and by fitting no-slip boundary conditions at the spherical surface. His result for drag force acting on the sphere was:

$$
F_{D}=3 \pi \mu_{f} d_{p} U_{o}
$$

where $U_{o}$ is the undisturbed free stream velocity.

When the particle velocity relative to the bulk fluid is equal to the undisturbed free stream velocity in eq. (7) and $\mathrm{Re}<0.6$, the drag coefficient $C_{D}$ in eq. (5) corresponding to the Stokes formula, eq. (7), can be expressed as

$$
C_{D}=\frac{F_{D}}{\frac{1}{8} \rho_{f} v_{f}^{2}\left(\pi d_{p}^{2}\right)}=\frac{24}{R e}
$$

$R e$, the dimensionless parameter used in eq. (8), is defined in terms of particle size $d_{p}$ and velocity $v_{f}$ relative to the fluid medium with density $\rho_{f}$ and viscosity $\mu_{f}$ as, 
$\operatorname{Re}=\frac{d_{p} \rho_{f} v_{f}}{\mu_{f}}$

When the drag coefficient $C_{D}$ in eq. (6) is replaced by eq. (8), settling velocity for a single spherical particle in quiescent fluid becomes

$v_{f}=\frac{g d_{p}{ }^{2}\left(\rho_{p}-\rho_{f}\right)}{18 \mu_{f}}$

It must be emphasized that Stokes's drag coefficient is only applicable at very low velocities and valid for values of Reynolds number less than about 1 . This limit for Stokes flow corresponds to viscous dominant settling velocity.

At larger values of the Reynolds number, the inertial terms exercise an increasing influence on the flow dynamics. From the literature, the drag coefficients for the spherical particle submerged in the fluid are as follows:

$$
\begin{aligned}
& C_{D} \approx \frac{18.5}{R e^{0.6}} \text { for } 1 \leq R e<10^{3} \text { (intermediate flow regime) } \\
& C_{D} \approx 0.44 \text { for } 10^{3} \leq R e<10^{5} \text { (Newton's flow regime) }
\end{aligned}
$$

The study of settling phenomena has been performed by a considerable diversity of approaches. The literature information (Oliver, 1961) has suggested that the motion of a typical single particle should be influenced by both the motion and the presence of the other particles. The main effect of the motion of the other particles is to cause a return flow of liquid, while the presence of the other particles produced an effect similar to an increase in the viscosity of the dispersing liquid. In the literature correlations, the velocity for flow past a single sphere was used in order to obtain an equation relating the settling velocity of a suspension of mono-size spherical particles to the volume concentration of the solid phase.

Table 3 shows various literature correlations for relative settling velocity $V_{r}$ in terms of solid volume concentration, $c$. Relative settling velocity $V_{r}$ is defined as

$$
V_{r}=\frac{v_{s}}{v_{f}}
$$

In eq. (12), $v_{s}$ is settling velocity in a multi-particle system, and $v_{f}$ is settling velocity for a single particle in a fluid.

The downward motion of the particles must cause an upward flow of liquid, and the velocity of this flow averaged for the whole flow cross-section of the tank must be the liquid fraction $(1-c)$ times the solid settling velocity of particles allowing only for return flow of liquid when $c$ is defined as the solid volume fraction of the suspended fluid. In addition, the presence of other particles also impedes the motion of a typical particle in the same way as if there were an increase in the viscosity of the liquid, so that the effective relative viscosity would reduce the settling rate of the suspended particles. Thus, the updated literature correlations [4] for settling velocity within a dilute solution were formulated considering these two factors.

$$
v_{s}=v_{f} f_{1}(c) f_{2}(c)
$$


In eq. (13) $f_{1}$ and $f_{2}$ are empirical functions associated with a return flow effect due to the falling of the particles and a hindering effect of the particle precipitation due to the increased effective viscosity, respectively. These two functions were assumed to be dependent only on the solid volume fraction of suspension, $c$.

Figure 5 shows single free-fall velocities and multi-particle settling velocities as function of solid particle diameters. The calculations were performed by using a Stokes's flow approach (eq. (10)) and the literature correlation for the settling rate of mono-sized spherical particles.

Typical literature correlations for relative settling velocity are shown in Table 3 to examine the interference or hindering effects of particle settling due to presence of the other particles for the range of solid particle concentrations. The results shown in the literature indicate that settling velocities of particles in a multi-particle system are different depending on the particle shape and solid concentration.

Volume concentration of particles in the continuous fluid phase is one of key parameters associated with flow pattern and slurry characteristics. Weight fraction $\mathrm{W}$ for solids can be converted to volume concentration $C$ for given densities of the fluid and solid phases.

$$
C_{v}=1-\left\{\frac{\left(\frac{\rho_{f}}{\rho_{s}}\right)}{\left(\frac{1}{W}-1\right)}+1\right\}^{-1}
$$

where $\rho_{f}$ and $\rho_{s}$ are the densities of fluid and solid, respectively.

From eq. (14) volume fractions of CST solids $\left(C_{v}\right)$ can be calculated as about 0.11 for the present operating conditions when their weight fractions in a slurry flow are 0.20 . 
Table 3. Literature correlations for relative settling velocities based on solid volume fraction as stated in Ref. 4 (relative settling velocity $V_{r}$ is defined by eq. (12)).

\begin{tabular}{|c|c|c|}
\hline Authors (Year) & Relative settling velocity correlations & Approach method \\
\hline Burgers (1942) & $V_{r}=\left\{1+\left(\lambda_{1}+\lambda_{2}\right) c\right\}^{-1}, \lambda_{1}=15 / 8, \lambda_{2}=5$ & Theoretical work \\
\hline Steinour (1944) & $V_{r}=(1-c)^{2} 10^{-1.82 c}$ & Empirical work \\
\hline Hawksley (1951) & $V_{r}=(1-c)^{2} \exp \left\{-\frac{2.5 c}{(1-0.609 c)}\right\}$ & Empirical work \\
\hline Oliver (1961) & $V_{r}=\left(1-0.75 c^{1 / 3}\right)(1-2.15 c)$ & $\begin{array}{c}\text { Theoretical and empirical } \\
\text { work }\end{array}$ \\
\hline
\end{tabular}

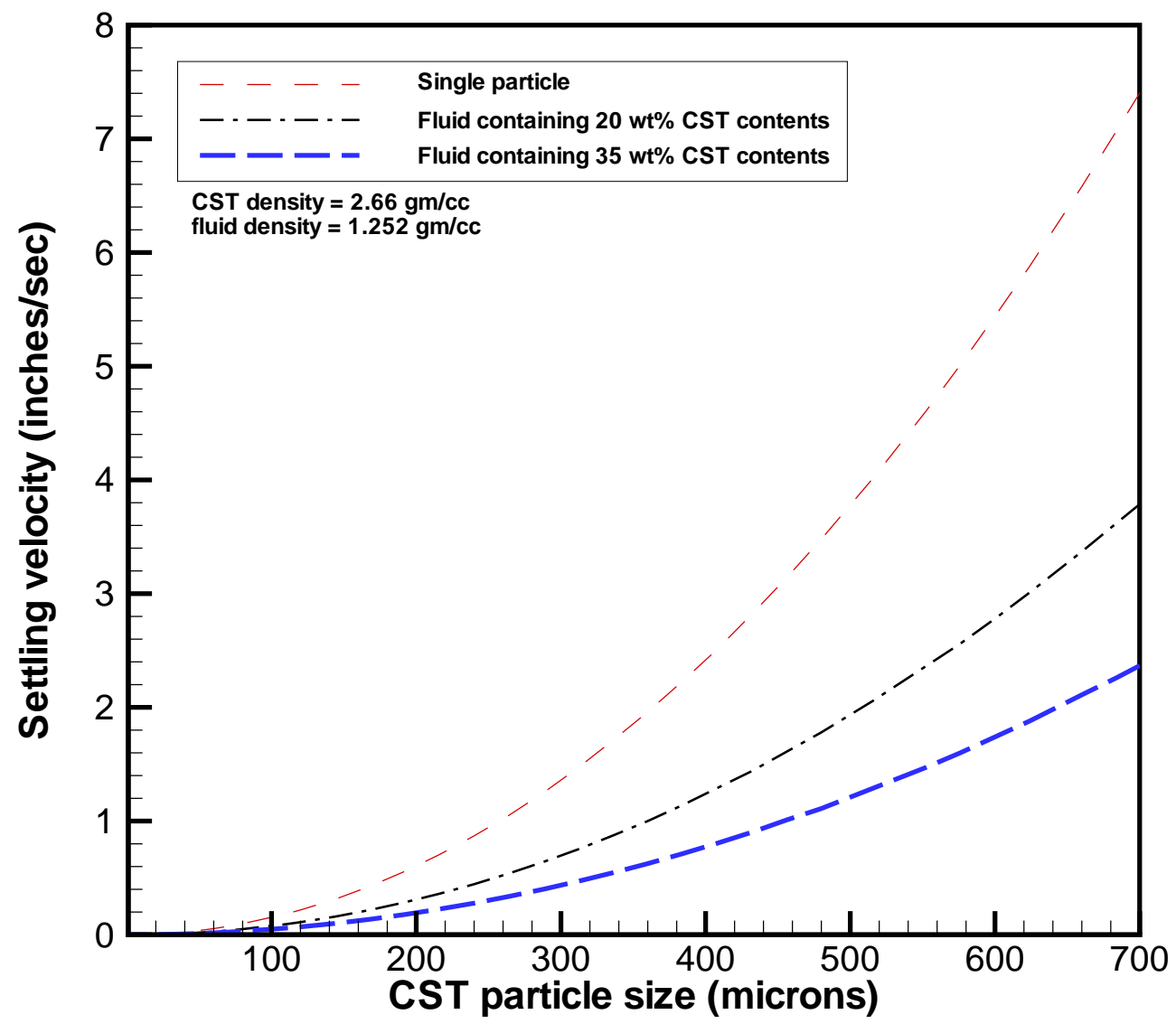

Figure 5. CST settling velocities as function of particle sizes for different solid contents in tank fluid using Oliver's correlation of Table 3 


\subsection{Modeling Approach Method}

The FLUENT ${ }^{\mathrm{TM}}$ [9] code, which was validated against velocity measurements in the fulltank facility located in TNX [7], was used to calculate waste flow patterns for the slurry mixers of Tank 40 to estimate the ability to suspend and remove sludge under potential operating conditions. In this work, the ability of the Fluent code to capture important flow phenomena associated with the flow mixing behavior of a submerged turbulent jet was demonstrated.

For the present work, four slurry pumps in Tank 40 provide flow circulation for CST suspension within the 85-ft tank. The pump suction is located at the bottom of the jet pump as shown in Fig. 1. A three-dimensional CFD analysis was performed to evaluate the flow patterns driven by a turbulent jet of the submersible slurry mixer. The pumps were assumed to be stationary for the steady state model. For a rotating model, the direction of the pump discharge was changed in discrete $22.5^{\circ}$ increments counterclockwise. The pump stayed fixed for 11.25 seconds at each direction, resulting in a simulated rotational speed of $1 / 3 \mathrm{rpm}$. The pump was started in a quiescent tank. The transient calculations were performed successively for $22.5^{\circ}$ increments of the pump orientation until a quasi-steady mixing flow pattern in the tank was reached.

The present analysis considers several basic cases with different operating conditions to investigate how sensitive the flow patterns are to indexed or rotating pump operating mode, number of operating pumps, and pump rotating speeds for given nominal operating conditions. The present work consists of two fundamental models. One is to perform the steady-state model for indexed stationary pump and different number of operating pumps under the reference design and operating conditions as provided by the customer [1]. The other is to study the transient modeling calculations for pump rotations with different numbers of operating pumps to evaluate the impact on flow circulation patterns. Both models were used to estimate flow patterns and effective suspension distance from the pump under nominal operational conditions with a fixed pump position or pump rotation, and to develop an operational strategy for suspension of the CST particles. In addition, the extent of the slurry mixing zone is estimated for a slurry mixer submerged at each of the four corners of the tank for given reference design and operating conditions.

Detailed modeling domain and operating conditions are provided in Fig. 1 and Table 1. The model geometry was created using body-fitted coordinates and unstructured multiblock grids to include internal solid structures of the tank under the CFD environment. Detailed wave motion of the free surface at the top of the tank was neglected for computational efficiency. That behavior does not have a significant impact on the flow patterns inside the fluid region in a deep tank since the ratio of liquid height above the nozzle to nozzle diameter is at least about 38 , which is much larger than the critical ratio of 2.5 found in the literature [8]. The fluid properties of water were evaluated at $50^{\circ} \mathrm{C}$. The flow conditions were assumed to be fully turbulent since Reynolds numbers for typical operating conditions were in the range of $10^{6}$ based on the pump nozzle inlet conditions. A standard two-equation turbulence model, the $k-\varepsilon$ model [9], was used, since previous work [7] showed that the two-equation model predicts the flow evolution of turbulent jet in a large stagnant fluid domain with reasonable accuracy. This model specifies the turbulent or "eddy" viscosity, $\mu_{t}$, by the empirical equation, 


$$
\mu_{t}=\left(\frac{C_{\mu} \rho_{f} k^{2}}{\varepsilon}\right)
$$

In eq. (15) $C_{\mu}$ is an empirical constant. In the present calculations, its value is 0.09 since the model was benchmarked against the data in the previous work [7]. The turbulent viscosity is computed by solving two transport equations for $k$ (turbulent kinetic energy) and $\varepsilon$ (rate of dissipation of turbulent energy). The governing equations to be solved for the present work are composed of one continuity equation, three momentum equations for the three component directions ( $x, y$, and $z$ directions), and two constitutive equations for the turbulence descriptions. Detailed descriptions for the governing equations and computational methods are provided in previous work [7].

\subsection{Tank 40 Model and Assumptions}

Tank 40 is cylindrical, $85 \mathrm{ft}$ in diameter, and $24.5 \mathrm{ft}$ high. For one of the reference operating conditions, the tank liquid level was kept 200 in high as shown in Table 1. Each pump has two horizontal discharge nozzles, each 3.625 in diameter. Fluid velocity at the exit of pump nozzle corresponding to a total discharge flowrate of $3800 \mathrm{gpm}$ per nozzle was used for the present calculations. There is a single suction at the bottom of the pump. The mixer is located about $13.5 \mathrm{ft}$ away from the tank wall boundary and the pump nozzle located about 12.375 in above the tank bottom. The modeling domain contains the internal flow obstructions representing the $6.75 \mathrm{ft}$ diameter central column to support the tank roof and four risers for pump mixers. Detailed dimensions and pump layouts in Tank 40 as modeled in the present work are illustrated in Fig. 6 . The model is a full three-dimensional representation of the entire tank to capture significant phenomena related to the turbulent behavior of the jet flow.

As mentioned earlier, two basic modeling approaches are taken for the present analysis. One is the steady state model with the reference operating conditions as shown in Table 1. This model is used to estimate effective mixing zone under steady-state operational conditions with an indexed pump position, and to develop an operational strategy for suspension of the CST particles. The other is the transient model with pump rotation to evaluate the flow circulation patterns due to the transient changing nozzle aiming direction. Water was used to simulate the fluid in the tank. Previous sensitivity results $[6,7]$ showed that flow pattern impacts due to fluid property differences were negligibly small. Detailed geometrical and operating conditions are provided in Table 1. Based on nozzle diameter and water properties, flow near the nozzle is clearly turbulent since the Reynolds number for the reference operating conditions is about $3.3 \times 10^{6}$. The flow for the entire computational domain is assumed to be turbulent for a reasonable representation of the liquid jet leaving the pump nozzle.

As discussed previously, the standard $k-\varepsilon$ model was used for the turbulence calculations. A three-dimensional model was run in steady-state and transient modes for the fixed pumps and rotating pumps to allow the turbulent jet flow to develop a flow pattern for the operating conditions of Tank 40 as provided in Table 1.

The calculations consisted of several different cases to simulate various operating conditions for Tank 40 and to examine the sensitivities of the operating parameters with respect to the efficiency of CST suspension. For instance, when two pumps are used for the steady-state model, the pumps are in a fixed orientation to maximize flow streams 
aimed at the overall CST suspension over the entire fluid domain of the tank. Both discharge jets are located at a horizontal plane 12.375 in above the tank bottom. For the modeling analysis, pump flowrate was $3800 \mathrm{gpm}$ per nozzle. Figure 7 shows threedimensional geometrical configurations as modeled in the CFD environment for the multi-pump simulations including the internal flow obstructions. For the simulations, a series of the modeling calculations will be performed in a fixed pump orientation and in a $1 / 3$ rpm pump rotation until an optimized flow pattern is established.

Geometrical simplifications and physical model assumptions are listed as follows:

- There are no solid obstructions in the tank other than the pump support structure, nozzle housing, and central support column as shown in Fig. 1 or Fig. 6.

- Two discharge nozzles are $180^{\circ}$ apart, aligned in straight and opposite directions.

- $\quad$ The pump nozzle for the steady state model is stationary, although in reality, the pump has a slight oscillation.

- $\quad$ The working liquid is water at $50^{\circ} \mathrm{C}$.

- The liquid region is bounded by a free surface at constant atmospheric pressure.

- The model is isothermal. No energy equation is calculated.

- The flow in the entire model domain is assumed to be turbulent to give a reasonable representation of the liquid jet leaving the pump nozzle.

- The wavy motion of the free surface due to the interaction with the discharge jet is neglected. Literature data [6] show that the surface wave effect is negligible when the ratio of liquid height above the nozzle to nozzle diameter is much larger than 2.5 . It is about 52 for each slurry mixer under nominal Tank 40 operations.

Three-dimensional numerical simulations are made for the Tank 40 modeling analysis. About a quarter million nodes for the three-dimensional computational domain shown in Fig. 7 have been established from the sensitivity studies of computational meshes. Typical hexahedral, non-uniform meshes for the Tank 40 model are shown in Fig. 8. 


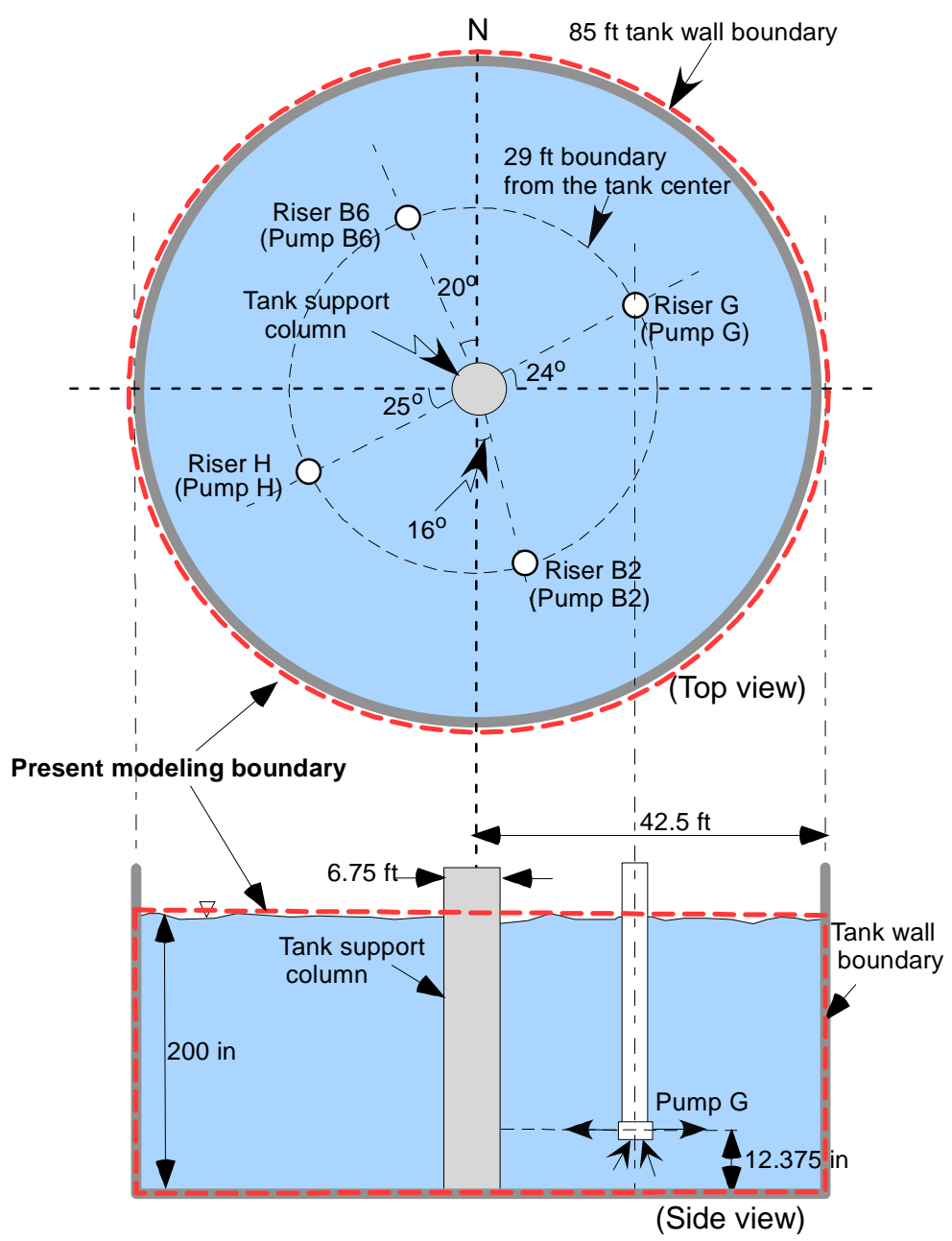

Figure 6. Three-dimensional modeling boundary for the present analysis of the Tank 40 facility with four slurry pumps 


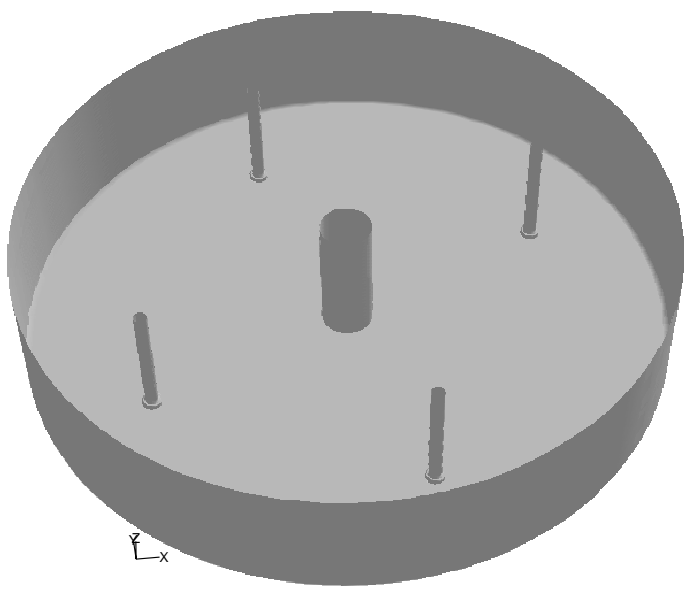

Figure 7. Three-dimensional computational domain as modeled for the present analysis

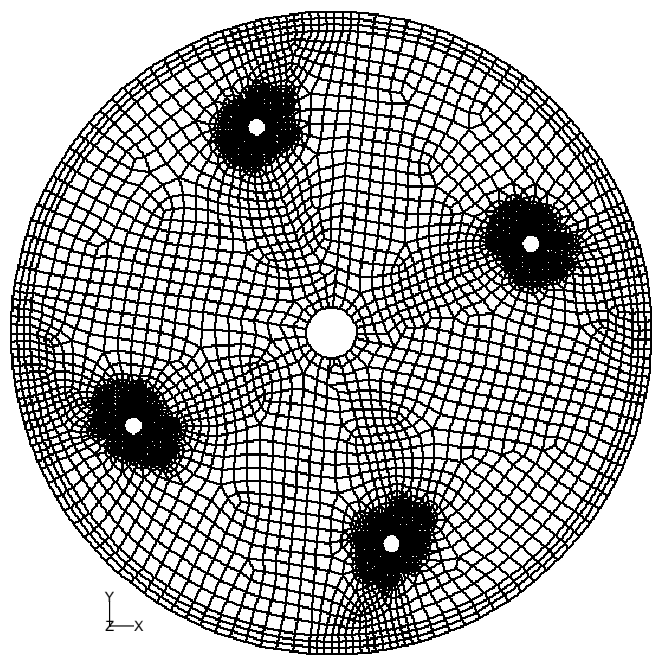

Figure 8. Hexahedral meshes on the $x-y$ computational domain for a three-dimensional CFD model of Tank 40 with four mixing pumps. 


\section{Results and Discussions}

CFD models have been developed and analyses performed to estimate circulation flow patterns within Tank 40 to evaluate the ability of the four slurry pumps to suspend the CST particles settled on the tank floor. The mixing pumps are assumed to be stationary or rotating. A flow velocity criterion will be used as the primary indicator of the ability to pick up and suspend the CST particles from the tank floor.

Two basic models were developed, including several different cases for the modeling calculations with internal flow obstructions such as four pump risers and central support column. One is the steady-state nominal model simulated with the reference operating conditions as provided by the customer [1], and it is mainly to evaluate flow circulation patterns and effective mixing zone to develop an operational strategy for the CST mixing operations of Tank 40. The other is the transient model, and its primary objective is to perform flow pattern analyses under pump rotation with given operational parameters such as pump flowrate, pump rotating speed, tank level, and pump elevation. Reference design and operating conditions of Tank 40 used for the present analysis are provided in Table 1.

For the steady state model, the pump is in a fixed orientation, so one discharge jet is pointed directly at the center of a horizontal plane in the tank, while the other is pointed directly at the outer wall. For the rotating model, the direction of the pump discharge was changed in discrete $22.5^{\circ}$ increments clockwise. The pump stayed fixed for 11.25 seconds at each direction, resulting in a simulated rotational speed of $1 / 3 \mathrm{rpm}$. The pump was started in a quiescent tank. The transient calculations were performed successively for $22.5^{\circ}$ increments of the pump orientation until a quasi-steady flow pattern in the tank was reached.

As shown in Fig. 6, a $6.75 \mathrm{ft}$ support column is located at the center of the tank. Each slurry pump is located at the 29-ft distance from the tank center. When the central column obstructs the jet flow generated by the pump, major questions are the optimum numbers of operating pumps and the most effective discharge direction of each pump to suspend the CST particles in case of indexed pump operation. The locations of the four slurry pumps within the three-dimensional modeling domain are shown in Fig. 6.

When all four operating pumps are aimed at the central support column, Figure 9 shows the calculation results for turbulent flow intensities on the pump discharge plane using the steady state model. The results show that four stagnant flow zones are generated between two adjacent pumps. As shown in the figure, flow jetted by pump nozzle is mainly dissipated by turbulent flow fluctuations due to the presence of solid boundary. The degree of turbulent dissipation is measured by turbulent intensity. It can be used as an indicator of local mixing associated with vortex eddy motion since solid boundary creates fluid vorticity. The turbulence intensity $I$ is defined as the ratio of the root-meansquare of the velocity fluctuations to mean flow velocity. That is,

$$
I=\frac{\sqrt{\frac{1}{3}\left(u^{\prime 2}+v^{\prime 2}+w^{\prime 2}\right)_{\text {avg }}}}{V} \approx 0.8165 \frac{\sqrt{k}}{V}
$$

In eq. (16) $u^{\prime}, v^{\prime}$, and $w^{\prime}$ are local velocity fluctuations in the $\mathrm{x}, \mathrm{y}$, and $\mathrm{z}$ directions and $v$ is the mean velocity magnitude. The turbulence intensity is proportional to the square root of the turbulent kinetic energy $k$ for a given mean fluid velocity. From the results 
shown in Figs. 9 and 10, the velocity reduction rate along the discharge direction increases with increasing turbulence intensity. This is mainly related to the increased radial dispersion of fluid momentum, which leads to diminished axial velocity of the nozzle discharge flow. CST mixing extents at the discharge plane of the pump and at the vertical plane crossing the two pumps, pump $\mathrm{G}$ and pump $\mathrm{H}$, are presented in Figs. 11 and 12. Red regions in the figures have local velocity magnitude larger than minimum suspension velocity required to scour 700 micron CST particle. It is noted that when four operating pumps are aimed at the central support column, fluid velocities jetted by the pumps are primarily dissipated at the tank wall boundary and around the central column of the tank, resulting in four dead mixing regions between the pumps as shown in Fig. 11.

The aiming directions for efficient flow patterns to maximize CST suspension region were obtained by guiding and rotating two adjacent jetted flows around the central column instead of direct flow interactions with the column. In this case, the most efficient flow patterns for the CST suspension with four indexed pump operations are shown in Fig. 13. As shown in Fig. 14, the turbulent intensities corresponding to the best aiming pump directions are more uniformly distributed over the entire flow domain, compared to those of the least efficient one in Fig. 9. Flow circulation patterns and fluid rotations driven by slurry pumps for the best aiming directions of four slurry pumps under the indexed pump operations are presented in Fig. 15. Results of the mixing extents at the discharge plane and at the vertical plane crossing the two pumps, pump $\mathrm{G}$ and pump $\mathrm{H}$, for the best aiming directions of four slurry pumps under the indexed pump operations are shown in Figs. 16 and 17, noting that the red regions have local velocity magnitudes larger than minimum velocity criterion required for suspending the 700 micron CST particles. As shown in Table 2, minimum velocity to pick up maximum CST particle of 700-micron diameter (as received) was estimated as $1.1 \mathrm{ft} / \mathrm{sec}$, assuming that the particles settled on the tank floor are not crushed, and they are not cohesive.

The effect of pump rotation on flow evolution and mixing extent was investigated by comparing the results of the two models, the steady state and transient models. When one slurry pump, pump $\mathrm{G}$, in Tank 40 is operated for similar operating conditions, comparisons of quasi-steady flow patterns between the stationary indexed and rotational operations are made in Fig. 18, showing that the red zone indicates the suspension zone of 700-micron CST particle. Figure 19 shows comparison of flow patterns between stationary indexed and rotational mode operations of two slurry pumps (pumps $G$ and $H$ ) in Tank 40 with the red zone of the 700-micron CST suspension. As shown in Fig. 20, velocity magnitudes along the principal discharge flow direction of pump $G$ are quantitatively compared between the two cases of indexed and rotational pump operations under two pump operations of pump $\mathrm{G}$ and $\mathrm{H}$. Table 4 compares the suspension distances from the pump nozzle exit to the point with local velocity equal to minimum suspension velocity of 700-micron CST particle between the two cases. When all four pumps are operated for CST suspension, quasi-steady flow patterns are compared in Fig. 21. Flow contours for the two cases are also shown in Fig. 22. Figure 23 shows that degree of fluid rotation for the rotating pump operations is more uniformly distributed than that of the indexed mode. Tank mixing with the pump rotations has better suspension capability of 700-micron CST than the other as shown in Fig. 24. The results show that the current capacity of all four pumps can hydraulically suspend CST particles over the entire domain of Tank 40. It is noted that total suspension extents of 700-micron CST particle for the two modeling cases have about the same area for given operating conditions other than pump operating mode although there is a difference of the suspension distance from the nozzle exit between them. 
When a slurry pump is operated in a rotating mode, it is important to estimate how long it takes to establish flow patterns for CST suspension. As shown in Fig. 25, the transient model results for $1 / 3 \mathrm{rpm}$ pump rotating speed show that it takes about 180 seconds to establish quasi-steady flow patterns when initial tank fluid is assumed to be quiescent. Figure 26 shows transient snapshots for flow patterns every 90 seconds after initial start of pump in quiescent tank when a single pump is operated with $1 / 3 \mathrm{rpm}$ rotational speed clockwise. Red regions in the figure have local velocity magnitudes larger than minimum velocity required for suspending 700 micron CST material under 200-in tank level, which is shown in Table 2. Figure 27 presents snapshots of quasi-steady flow patterns for one pump run with $1 / 3 \mathrm{rpm}$ rotational speed. When quasi-steady flow pattern is established for one pump run, transient velocity distributions with $1 / 3 \mathrm{rpm}$ rotational speed along the centerline crossing the central column of Tank 40 are shown in Fig. 28. The results show that during one-pump mixing operation with $1 / 3 \mathrm{rpm}$ pump rotational speed, maximum time interval to allow for settling of 700-micron CST particles is about 90 seconds. Using the settling velocity shown in Fig. 4a, settling time for 700 micron CST particle in 200-in tank level is found to be about 84 seconds when the CST solid precipitates in quiescent liquid medium containing $35 \mathrm{wt} \%$ (or $20 \mathrm{vol} \%$ ) CST solids. In this case, 700-micron CST solids in slower flow region such as upstream wall region may be settled on the tank floor since maximum time interval of 90 seconds allowing for settling during one pump run provides enough time to get the settling of CST particles.

Flow patterns established by the simultaneous run of two rotating pumps with pumps $G$ and $\mathrm{H}$ are shown in Fig. 29. Quasi-steady velocity distributions along the tank centerline crossing the central column are shown in Fig. 30. The results show that maximum time interval to keep local velocity magnitude lower than minimum suspension velocity (i.e., $1.1 \mathrm{ft} / \mathrm{sec}$ ) of 700 micron CST particle is about 80 seconds for simultaneous operations of two pumps with each pump rotated $1 / 3 \mathrm{rpm}$ speed. This non-suspension time provided by the two-pump run is slightly smaller than the settling time of 700 micron particle in fluid medium containing $35 \mathrm{wt} \%$ CST solids so that the CST materials may be kept suspended with two-pump run. Figure 31 shows flow patterns established by fourpump simultaneous run with $1 / 3 \mathrm{rpm}$ rotating speed. Local velocity magnitudes along the centerline of Tank 40 are presented in Fig. 32. Non-suspended time interval established by the four-pump run is found to be shorter than the settling time of maximum CST particle size (700 microns) in the 200-in tank level with $35 \mathrm{wt} \%$ CST contents. In this case the 700-micron solids may be kept suspended for the referenced tank level with 35 wt\% CST contents. However, when CST particles of 400-micron diameter, corresponding to average size as received, are stirred by four pumps with $1 / 3$ rpm rotating speed, the results demonstrate that they can be kept suspended as shown in Fig. 33. In this case, settling time of the 400-micron CST particles is about 161 seconds when they are initially at top surface of quiescent tank fluid. All the results are summarized in Table 5.

A series of different calculations was performed to evaluate CST suspension capabilities for three different numbers of operating pumps under the reference operating conditions as shown in Table 1 . They are simultaneous operations of 1, 2, and 4 pumps with each pump rotated $1 / 3 \mathrm{rpm}$ speed. For instance, the calculation results for the two-pump run showed that the local velocity for the rotational case is smaller than that of the stationary case far downstream from the jet nozzle as shown in Fig. 20, but their suspension areas denoted as the red regions in Fig. 19, are about the same. The difference in the suspension distance from the nozzle exit between the two cases ranges from about $35 \%$ to $50 \%$ at $50 \mathrm{ft}$ from the pump depending on the number of operating pumps. Comparison of the results for the two-pump run is shown in Fig. 20. The results for the 
Report: WSRC-TR-2004-00207

Date: $\quad 6 / 14 / 2004$

Page: $\quad 24$ of 48
WESTINGHOUSE SAVANNAH RIVER COMPANY

CST SUSPENSION ANALYSIS FOR SLURRY PUMPS OF TANK 40

transient model showed that quasi-steady flow patterns were established about 3 minutes after starting the pump in a quiescent liquid domain with a $3800 \mathrm{gpm}$ flowrate per nozzle and $1 / 3 \mathrm{rpm}$ rotational speed. This information will assist in the CST suspension and mixing plans for Tank 40 operations.

Table 4. Comparison of quasi-steady suspension distance of 700-micron CST particle between stationary indexed operations and rotational mode operations of two slurry pumps (pumps $\mathrm{G}$ and $\mathrm{H}$ ) in Tank 40

\begin{tabular}{|c|c|c|}
\hline Pump operation mode & $\begin{array}{c}\text { Nozzle exit } \\
\text { velocity } \\
\text { (ft/sec) }\end{array}$ & $\begin{array}{c}\text { Distance from the nozzle exit to the location } \\
\text { where minimum velocity required to suspend } \\
700 \text { micron CST is reached (ft) }\end{array}$ \\
\hline Indexed stationary pump & 118.1 & 66.1 \\
\hline Rotating pump & 118.1 & 60.3 \\
\hline
\end{tabular}

Table 5. Comparison of settling times of 700-micron CST particle between maximum settling time allowable during various numbers of pump operations and free settling velocity of quiescent fluid medium in Tank 40

\begin{tabular}{|c|c|c|c|c|c|c|}
\hline \multirow{3}{*}{$\begin{array}{l}\text { Number of } \\
\text { operating } \\
\text { pumps }\end{array}$} & \multirow{3}{*}{$\begin{array}{l}\text { Nozzle } \\
\text { exit } \\
\text { velocity } \\
\text { (ft/sec) }\end{array}$} & \multirow{3}{*}{$\begin{array}{l}\text { Max. settling } \\
\text { time* of } 700- \\
\text { micron CST } \\
\text { during tank } \\
\text { mixing with } \\
1 / 3 \text { rpm pump } \\
\text { rotation } \\
\text { (seconds) }\end{array}$} & \multicolumn{4}{|c|}{$\begin{array}{l}\text { Settling time }{ }^{\#} \text { for a quiescent fluid medium containing } 10 \text { or } 20 \\
\text { vol\% CST in 200-in tank level } \\
\text { (seconds) }\end{array}$} \\
\hline & & & \multicolumn{3}{|c|}{$\begin{array}{l}20 \text { wt } \% \text { CST } \\
\text { (10.5 vol. } \%)\end{array}$} & $\begin{array}{l}35 \text { wt\% CST } \\
\text { (20.2 vol. } \%)\end{array}$ \\
\hline & & & 300 microns & 400 microns & 700 microns & 700 microns \\
\hline 1 & 118.1 & $\sim 90$ & \multirow{3}{*}{287} & \multirow{3}{*}{161} & \multirow{3}{*}{53} & \multirow{3}{*}{84} \\
\hline 2 & 118.1 & -80 & & & & \\
\hline 4 & 118.1 & $\sim 70$ & & & & \\
\hline
\end{tabular}

Note:* Time duration to have fluid velocity lower than min. suspension velocity of 700-micron CST \# Settling time was estimated for 200-in traveling distance of a given particle size.

In the calculations, volume of non-cohesive CST material precipitated on the tank floor is not considered. That is, the deposition would be expected to follow behind the rotational motion of the jet, leaving an annular ring at the peripheral region near the tank wall. The particulate would remain there until the opposing jet is passed over that same region. 
The modeling results demonstrate that the pump rotations provide more active flow patterns with respect to the indexed pump operations, leading to larger suspension capabilities of CST particles. It is emphasized that the more operating pumps and the higher pump rotating speed are more efficient become better in terms of CST suspension capability since maximum settling time during the pump operations becomes smaller with number of rotating pump operations increased as shown in table 5 . This information will assist in the CST suspension and mixing plans for Tank 40 operations. The steady-state flow patterns on the horizontal discharge plane follow a series of parabolic curves similar to that of a free jet [13].
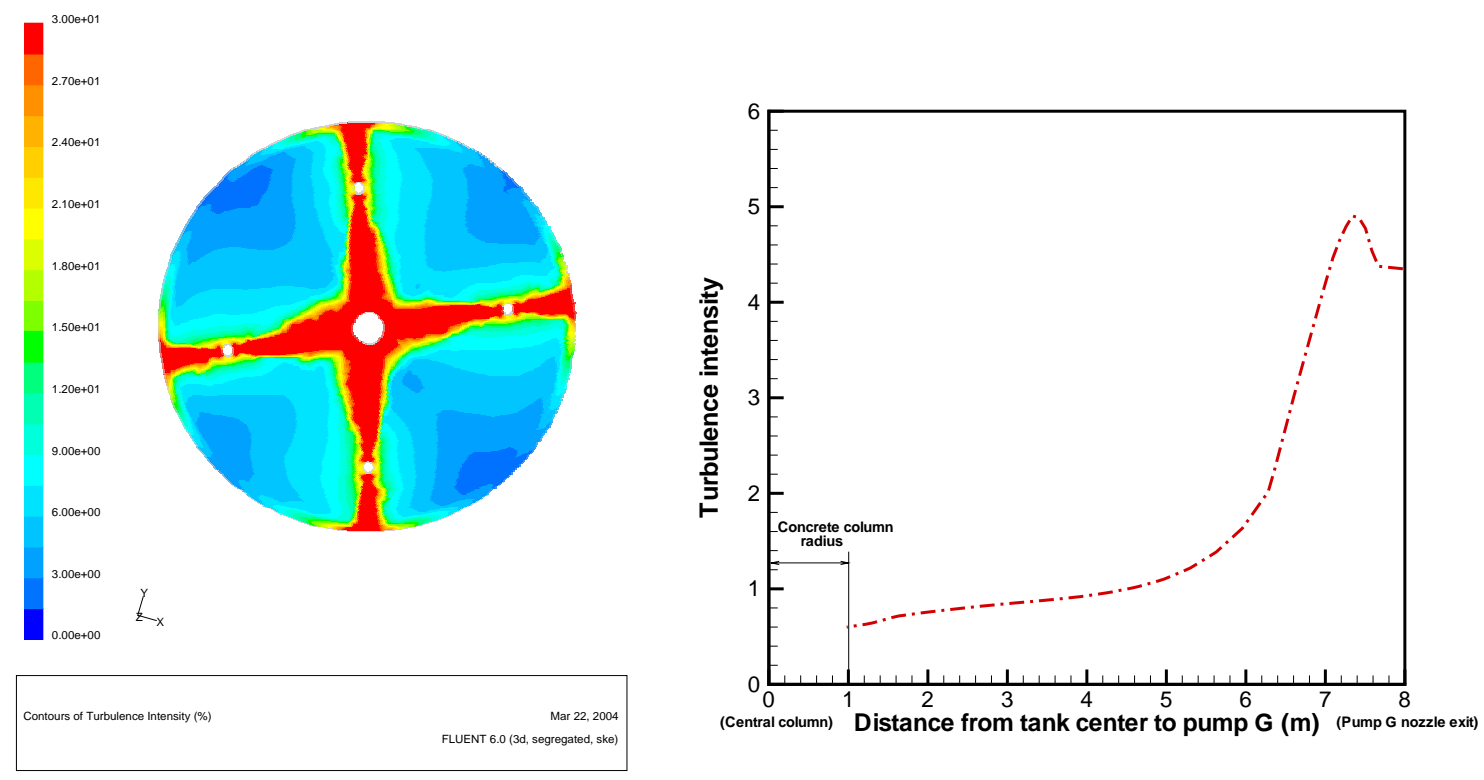

Figure 9. Turbulence intensity distributions at the discharge plane of the pump in Tank 40 showing the red region indicates the flow fluctuation larger than $30 \%$ of local average velocity magnitude 
Report: WSRC-TR-2004-00207

Date: $\quad 6 / 14 / 2004$

Page: $\quad 26$ of 48

\section{WESTINGHOUSE SAVANNAH RIVER COMPANY}

CST SUSPENSION ANALYSIS FOR SLURRY PUMPS OF TANK 40
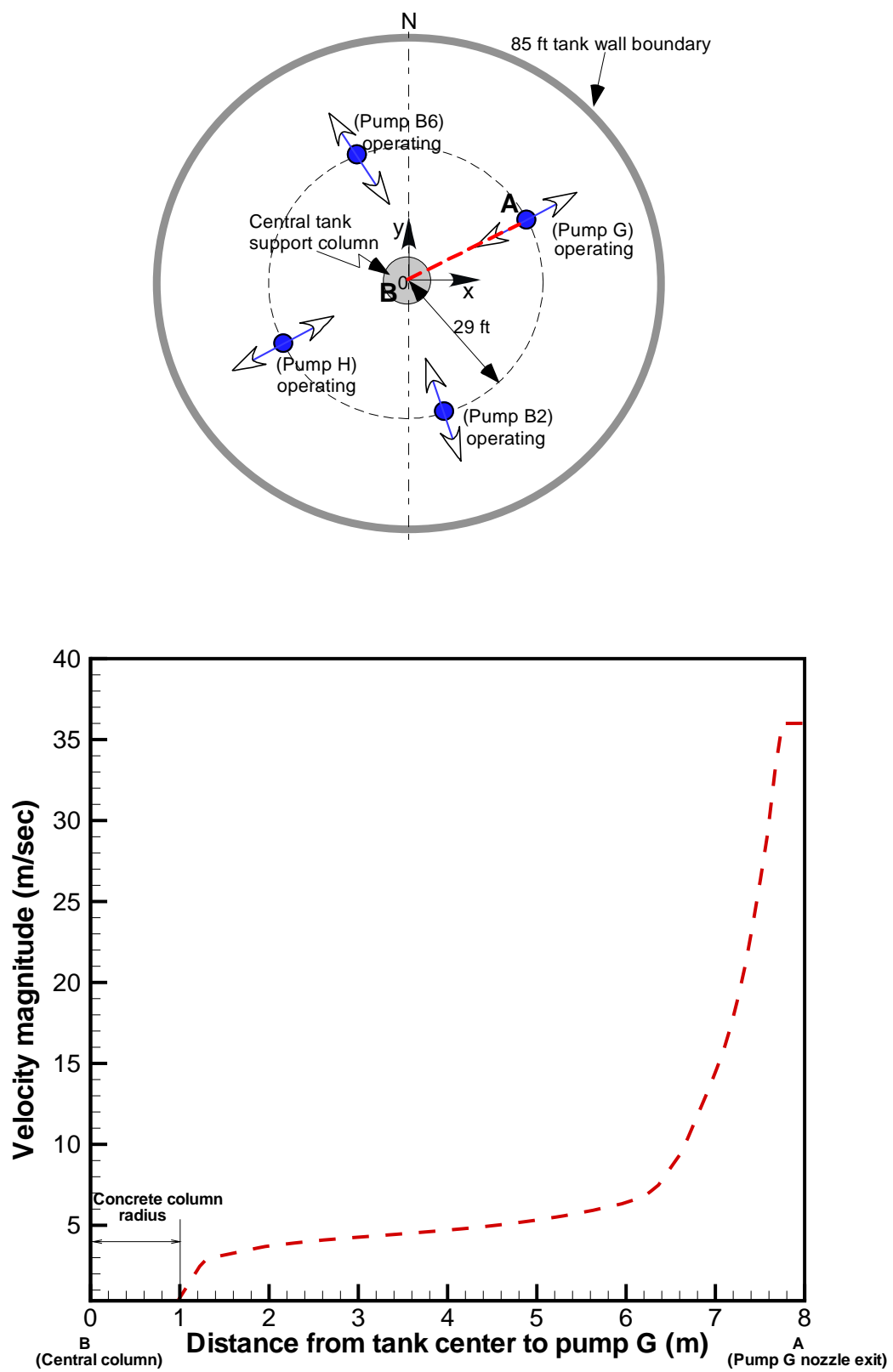

Figure 10. Velocity magnitude distributions along the principal discharge direction of pump $\mathrm{G}$ in Tank 40 

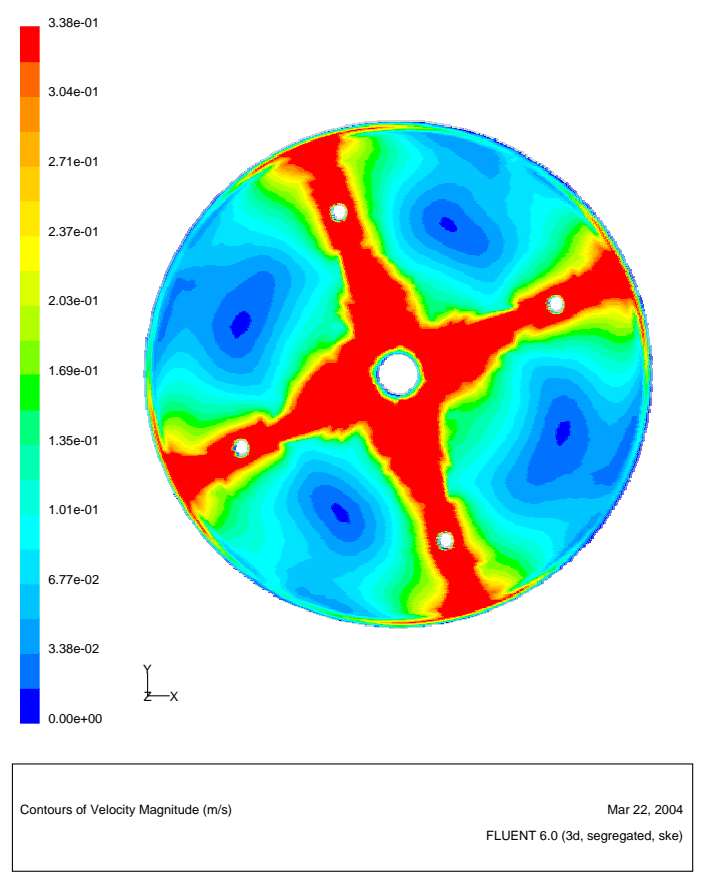

Figure 11. CST suspension zones at the discharge plane of the pump in Tank 40 showing the red region has the velocity magnitude larger than minimum velocity required to suspend 700 micron CST particle

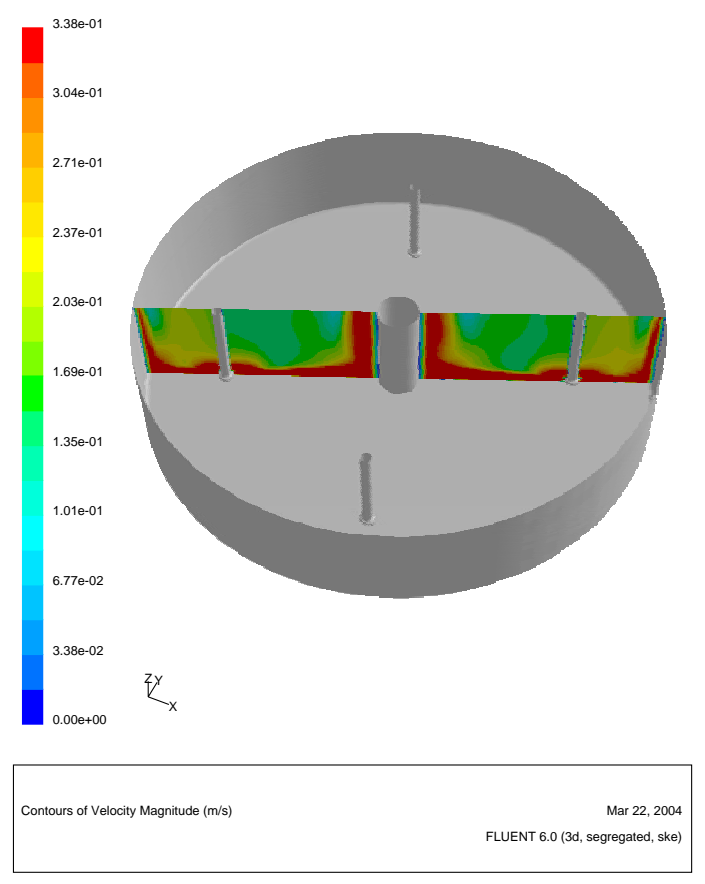

Figure 12. CST suspension zones at the vertical plane crossing two pumps, pump $G$ and pump $\mathrm{H}$, in Tank 40 showing the red region has the velocity magnitude larger than minimum velocity required to suspend 700 micron CST particle 


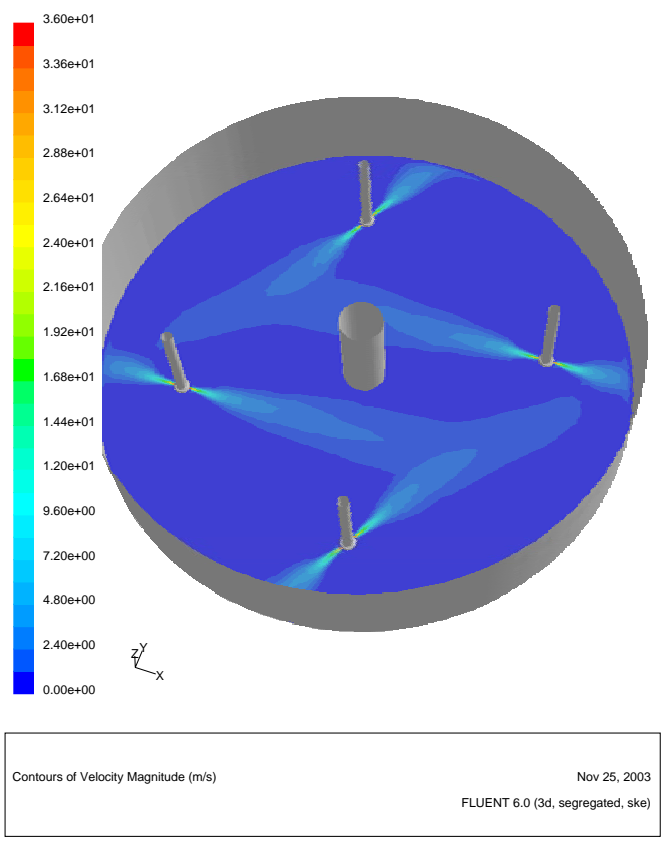

Figure 13. Flow circulation patterns for the best aiming directions to maximize suspension region of CST particles with four pumps operated in indexed nozzle positions
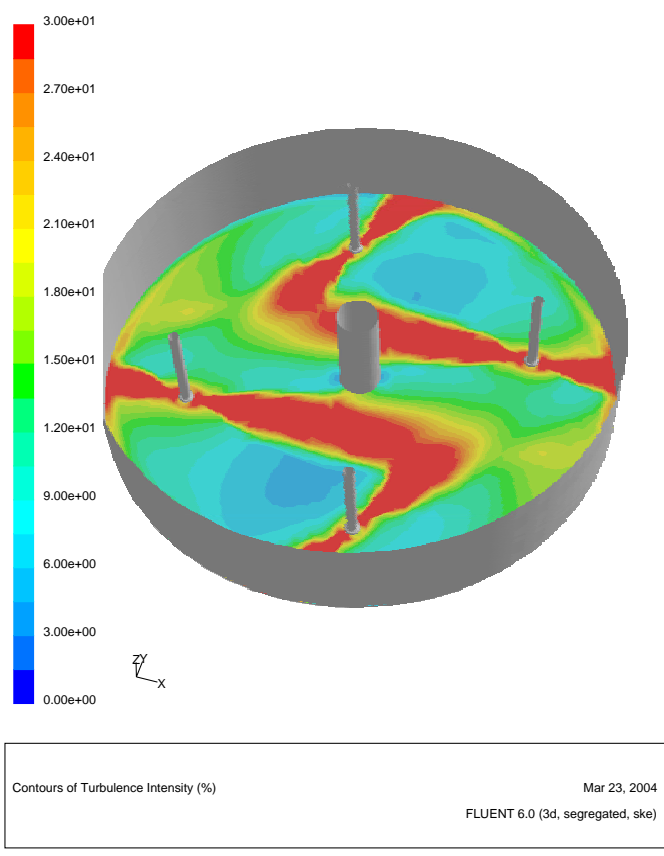

Figure 14. Turbulence intensity distributions at the discharge plane of the pump in Tank 40 showing the red region indicates the flow fluctuation larger than $30 \%$ of local average velocity magnitude 

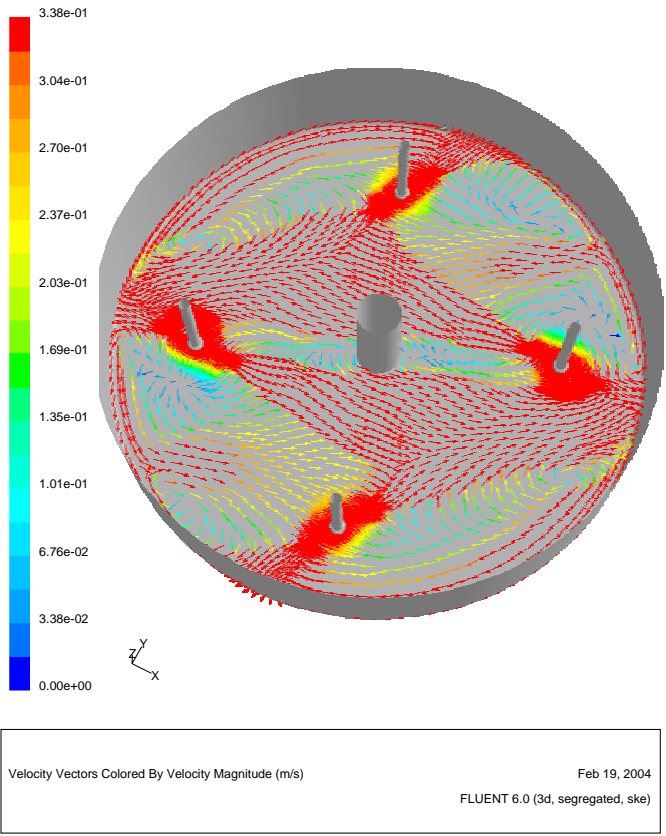

(Flow circulation patterns at the discharge plane)
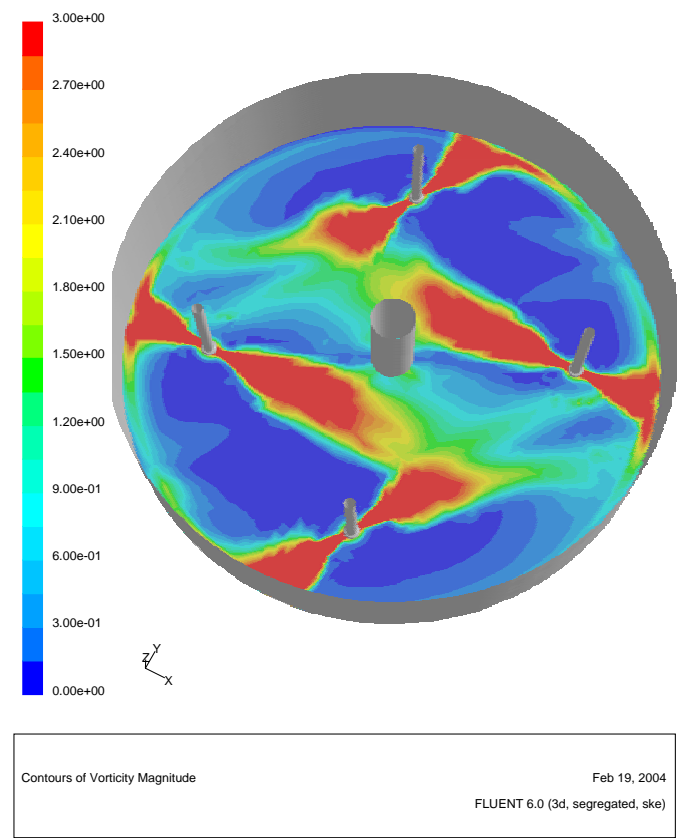

(Fluid rotations at the discharge plane)

Figure 15. Flow circulation patterns and fluid rotations driven by slurry pumps for the best aiming directions of four slurry pumps under the indexed pump operations 


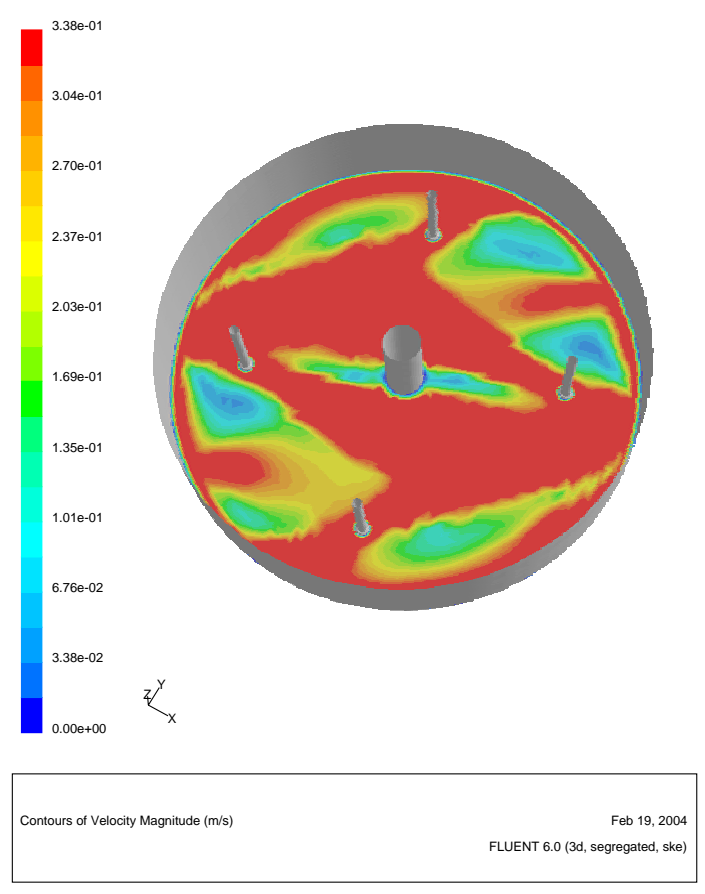

Figure 16. Flow circulations at the discharge plane for the best aiming directions of four slurry pumps under the indexed pump operations showing that red zone has higher velocity required to suspend the 700 micron CST particles

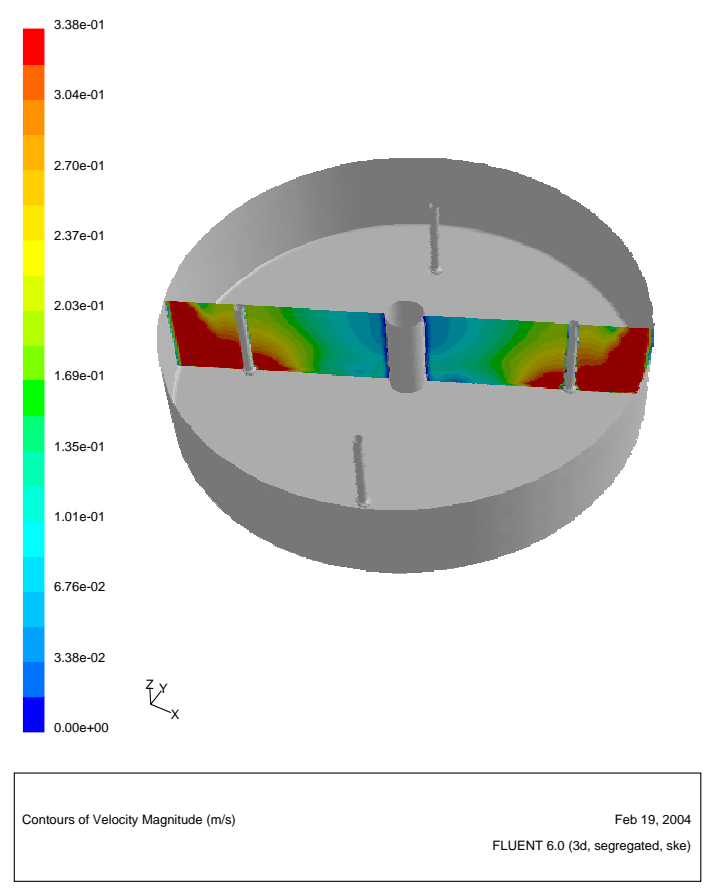

Figure 17. Flow circulations for four pump operations at the vertical plane crossing the two pumps, pump $\mathrm{G}$ and pump $\mathrm{H}$, for the best aiming directions of four slurry pumps under the indexed pump operations showing that red zone has higher velocity required to suspend the 700 micron CST particles 


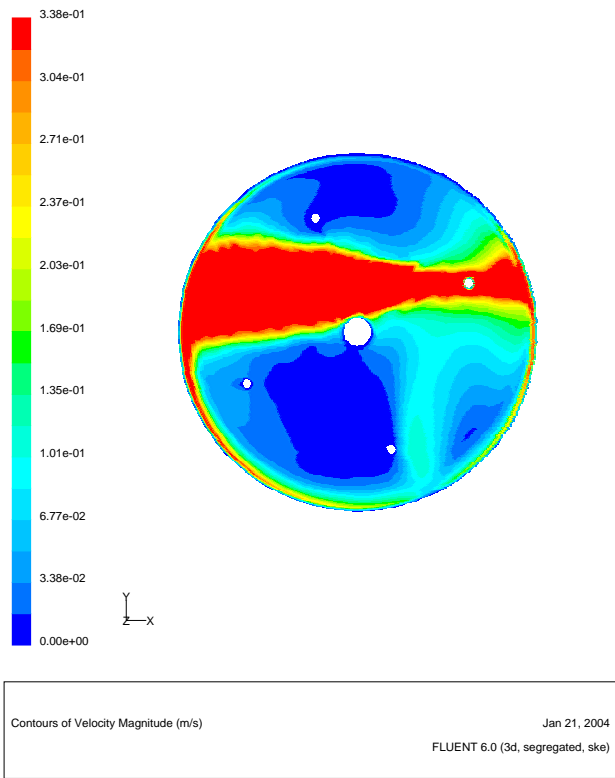

(Stationary indexed pump operations)

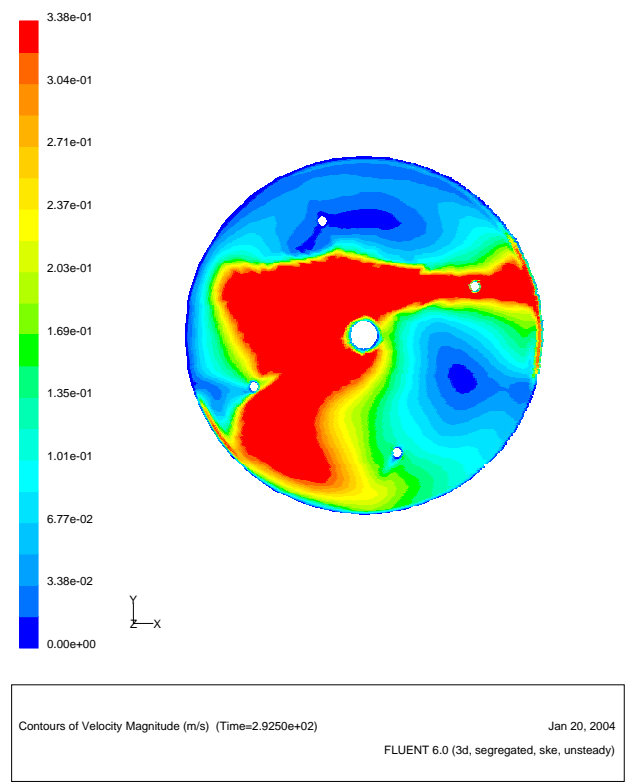

(Rotational pump operations)

Figure 18. Comparison of quasi-steady flow patterns between stationary indexed operations and rotational mode operations of one slurry pump (pumps $G$ ) in Tank 40 showing that the red zone indicates the suspension zone of 700 micron CST
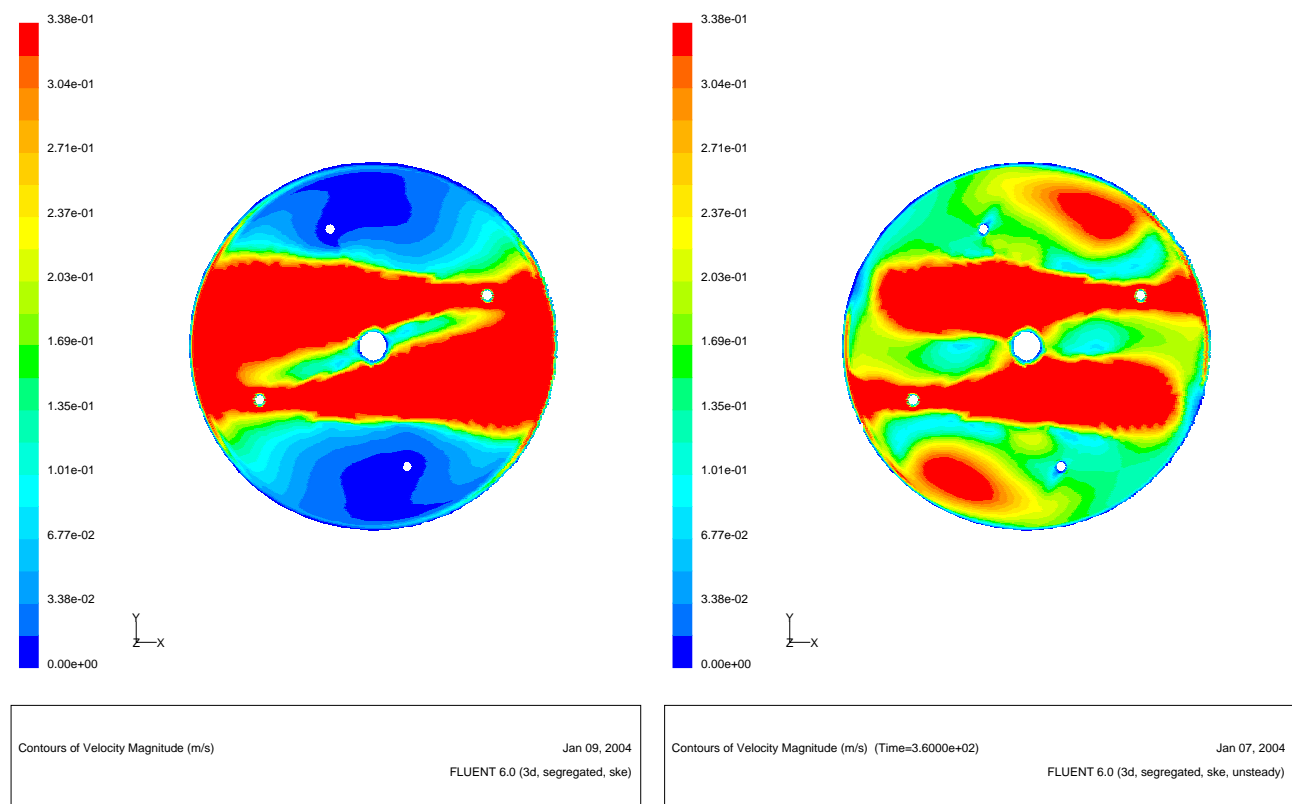

(Stationary indexed pump operations) (Rotational pump operations)

Figure 19. Comparison of quasi-steady flow patterns between stationary indexed operations and rotational mode operations of two slurry pumps (pumps $G$ and $\mathrm{H}$ ) in Tank 40 showing that the red zone indicates the suspension zone of 700 micron CST 

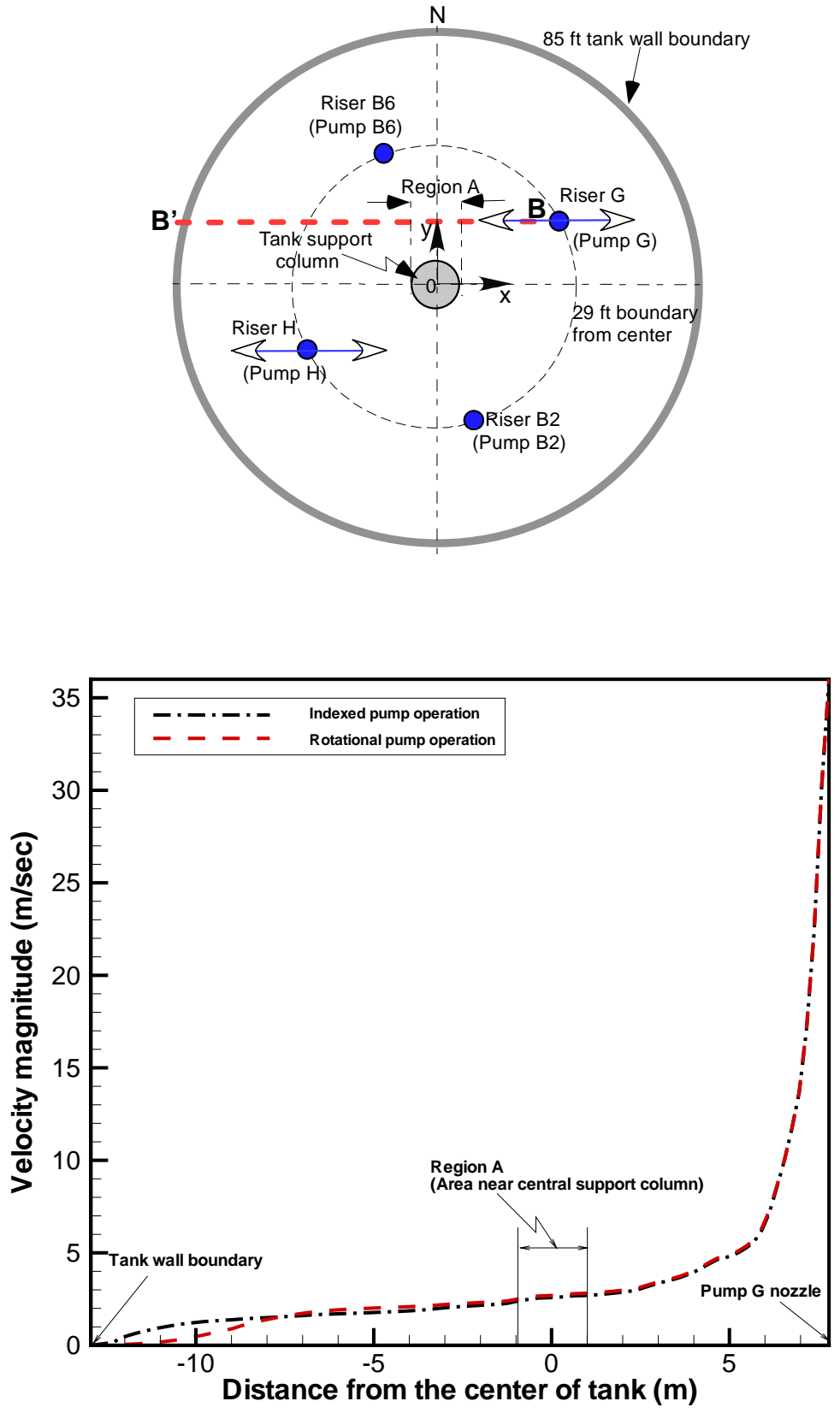

Figure 20. Quantitative comparison of velocity magnitudes along the principal discharge flow direction (line B-B') of pump $G$ for indexed and rotational pump operations under two pump operations of pump $\mathrm{G}$ and $\mathrm{H}$ 

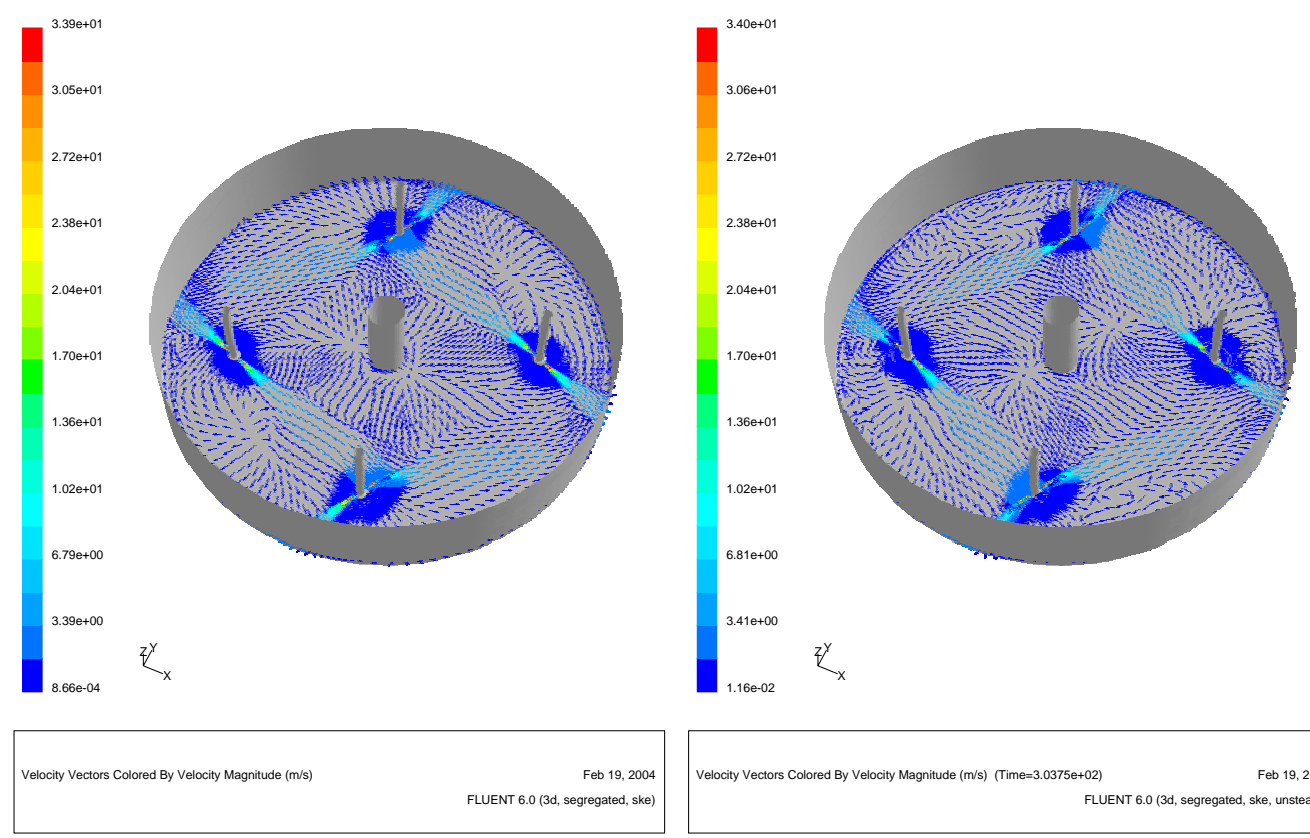

(Stationary indexed pump operations)

(Rotational pump operations)

Figure 21. Comparison of quasi-steady flow patterns between stationary indexed operations and rotational mode operations of four slurry pumps (pumps B2, B6, G, and H) in Tank 40

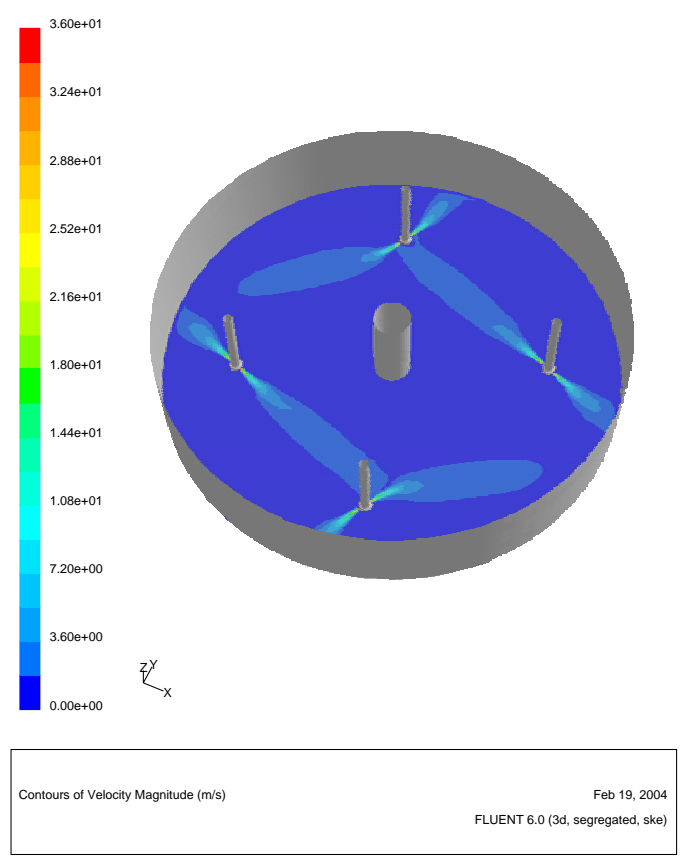

(Stationary indexed pump operations)

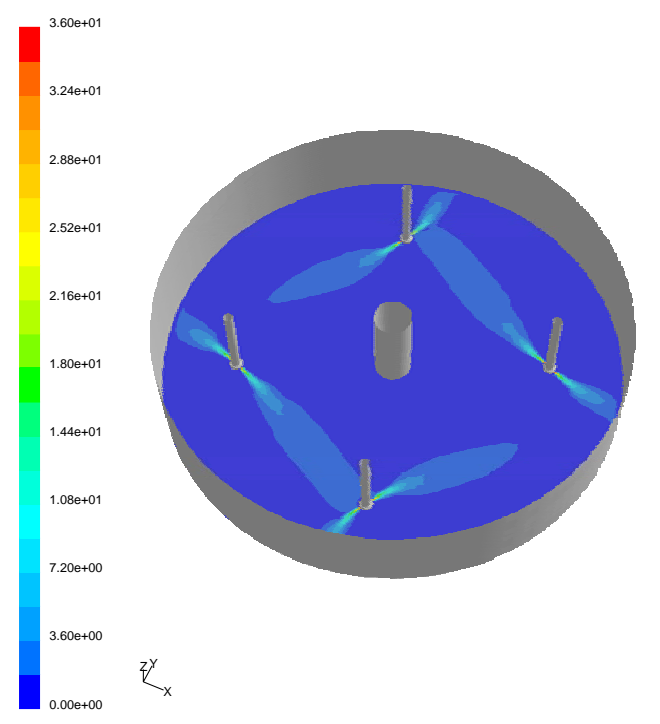

Figure 22. Comparison of quasi-steady flow patterns between stationary indexed operations and rotational mode operations of four slurry pumps (pumps B2, B6, $G$, and $H$ ) in Tank 40 


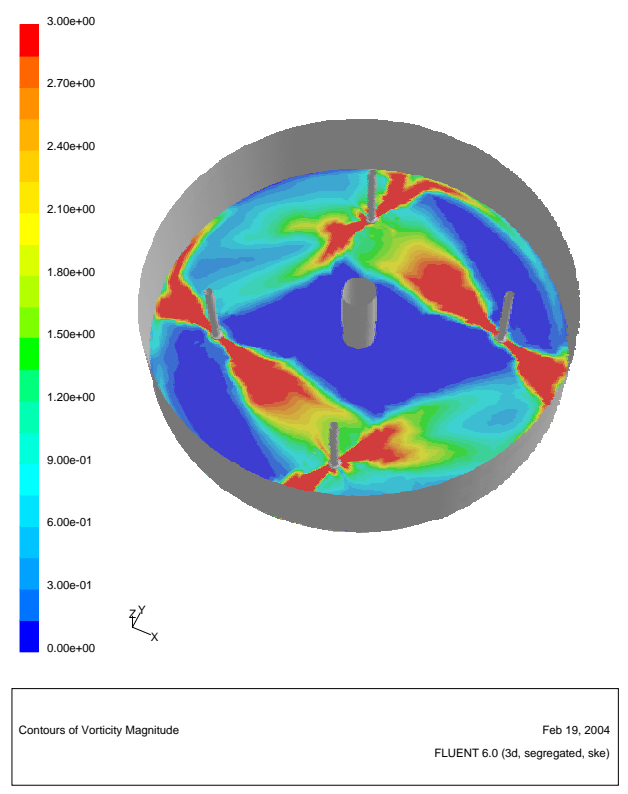

(Stationary indexed pump operations)

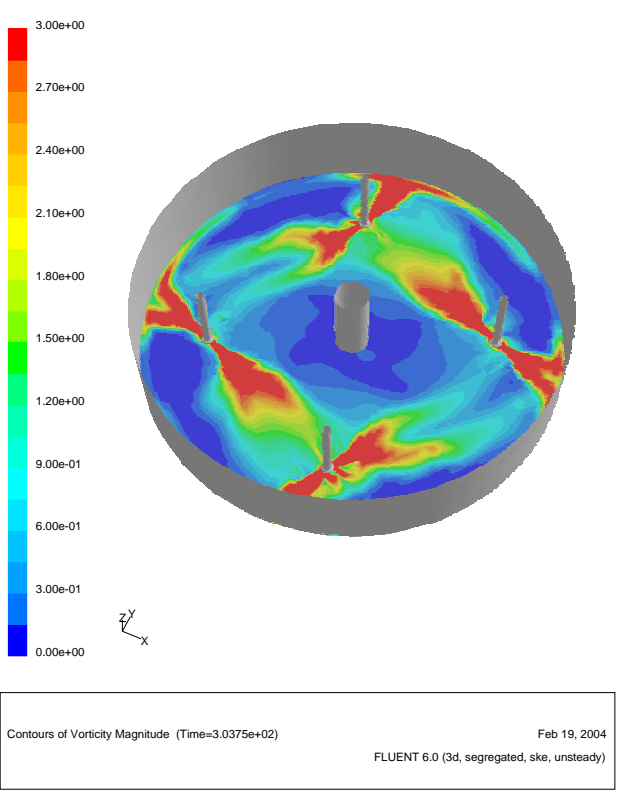

(Rotational pump operations)

Figure 23. Comparison of quasi-steady fluid rotations between stationary indexed operations and rotational mode operations of four slurry pumps (pumps B2, $B 6, G$, and $H$ ) in Tank 40 showing that the red zone indicates the suspension zone of 700 micron CST
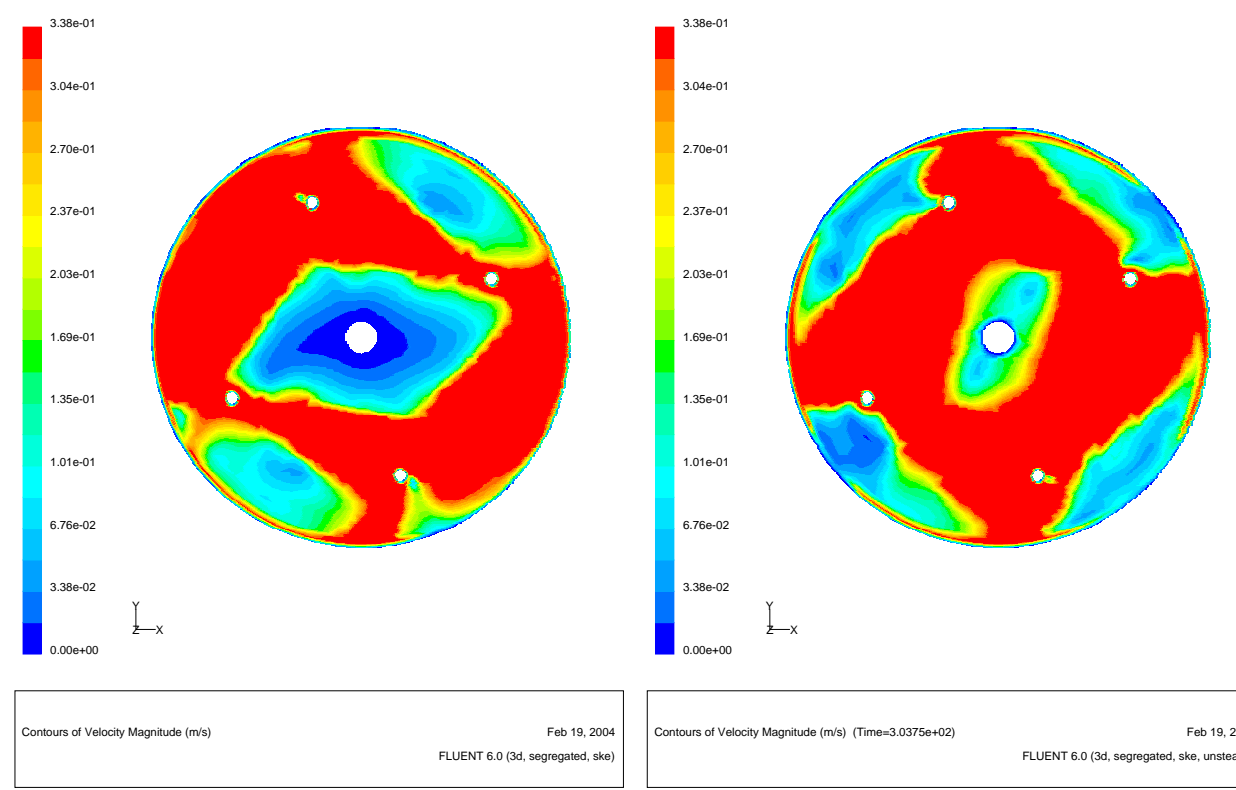

(Stationary indexed pump operations) (Rotational pump operations)

Figure 24. Comparison of quasi-steady flow patterns between stationary indexed operations and rotational mode operations of four slurry pumps (pumps B2, $\mathrm{B} 6, \mathrm{G}$, and $\mathrm{H}$ ) in Tank 40 showing that the red zone indicates the suspension zone of 700 micron CST 

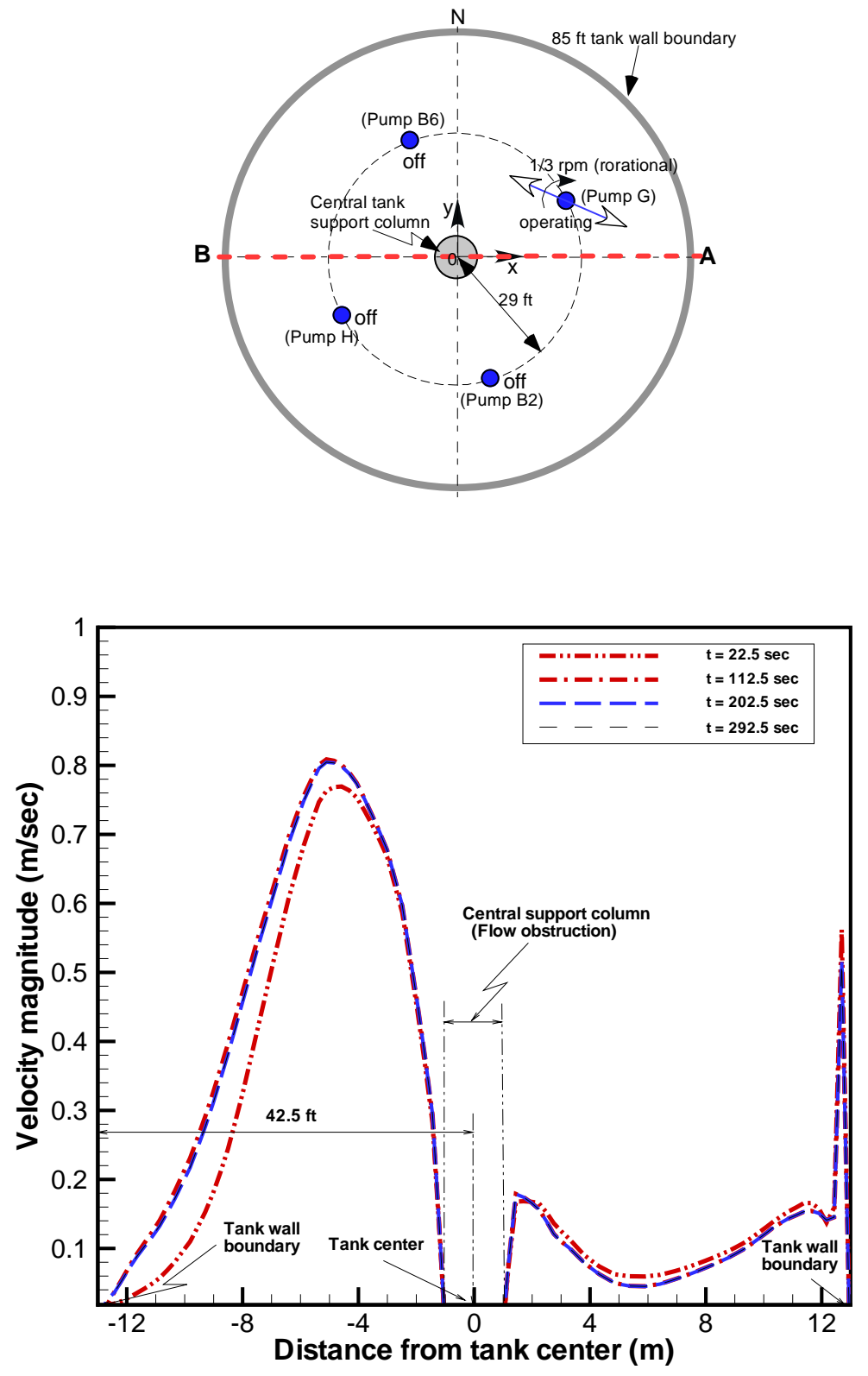

Figure 25. Transient flow velocity distributions along the centerline A-B of the tank at the elevation of the pump discharge nozzle for rotational operation of one slurry pump (pumps $\mathrm{G}$ ) in Tank 40 showing that transient time to reach steady state is about 180 seconds 
Report: WSRC-TR-2004-00207

Date: $\quad 6 / 14 / 2004$

Page: $\quad 36$ of 48

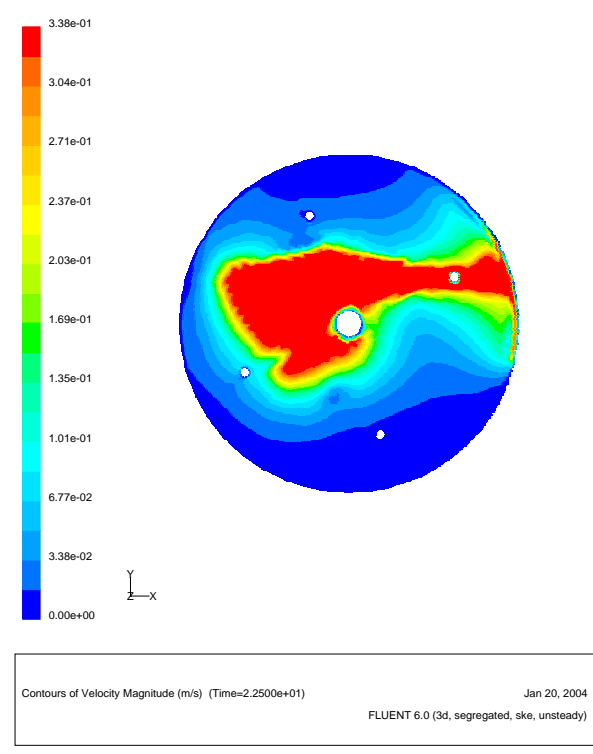

$(t=22.5 \mathrm{sec})$

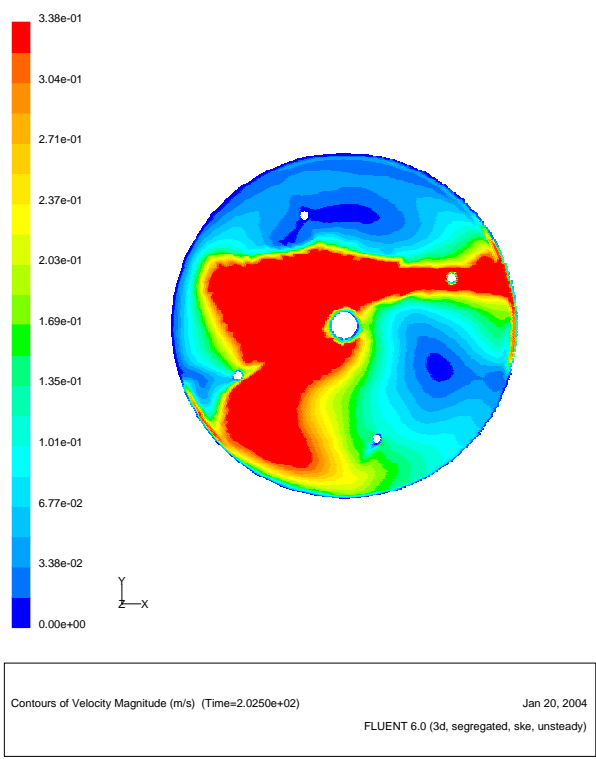

$(t=202.5 \mathrm{sec})$

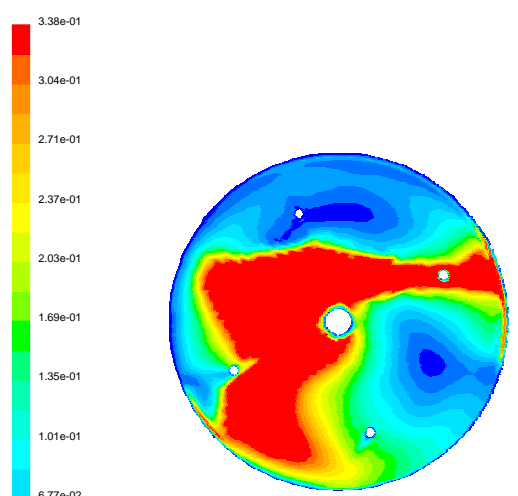

$I_{x}$

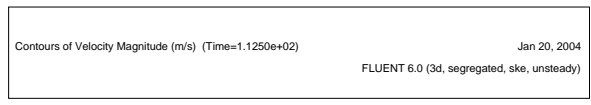

$(\mathrm{t}=112.5 \mathrm{sec})$
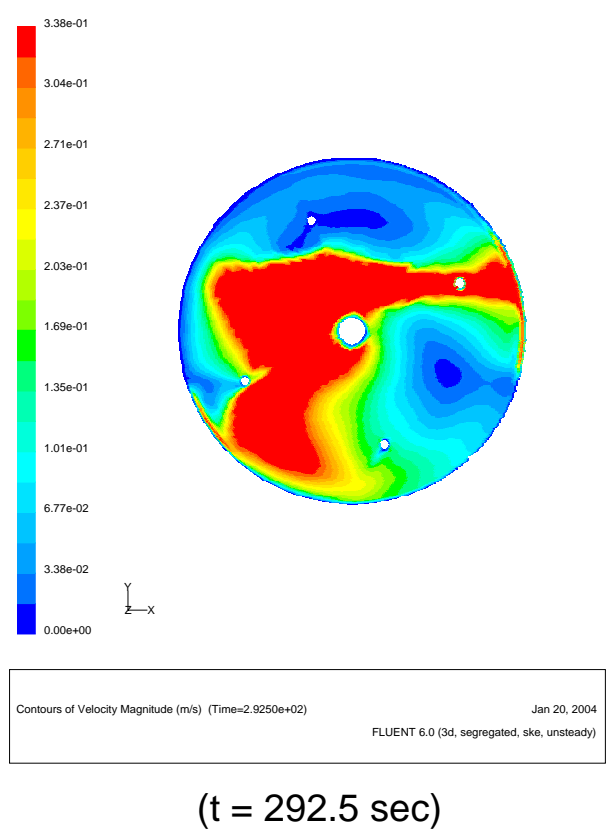

Figure 26. Transient flow patterns for one pump run with $1 / 3 \mathrm{rpm}$ rotational speed showing that the red zone indicates the suspension zone of 700 micron CST. 

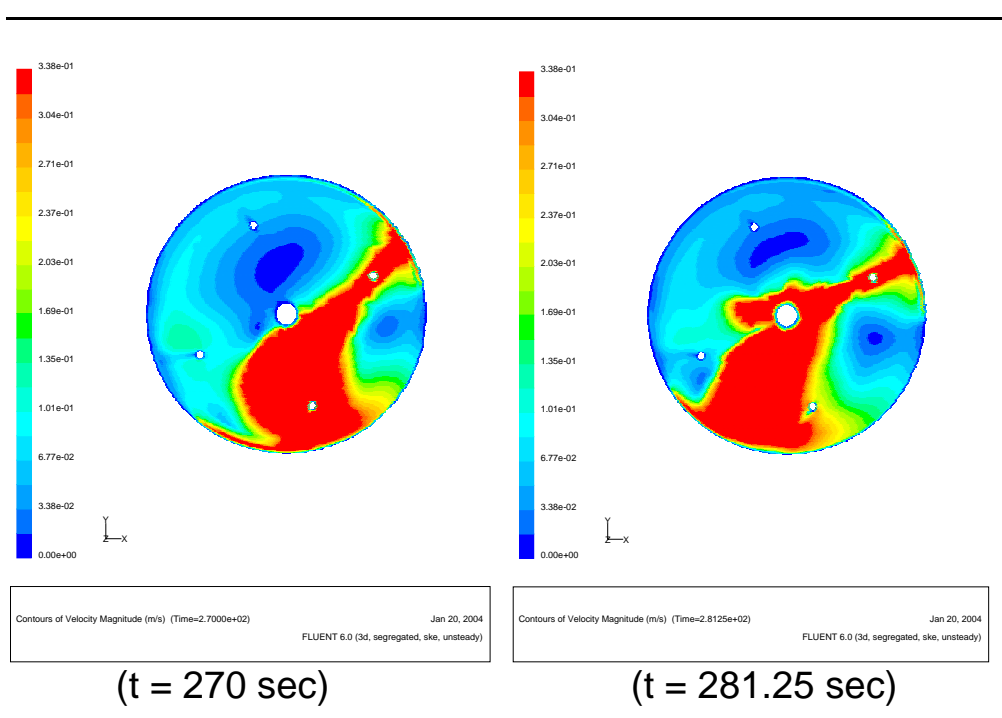

Page:
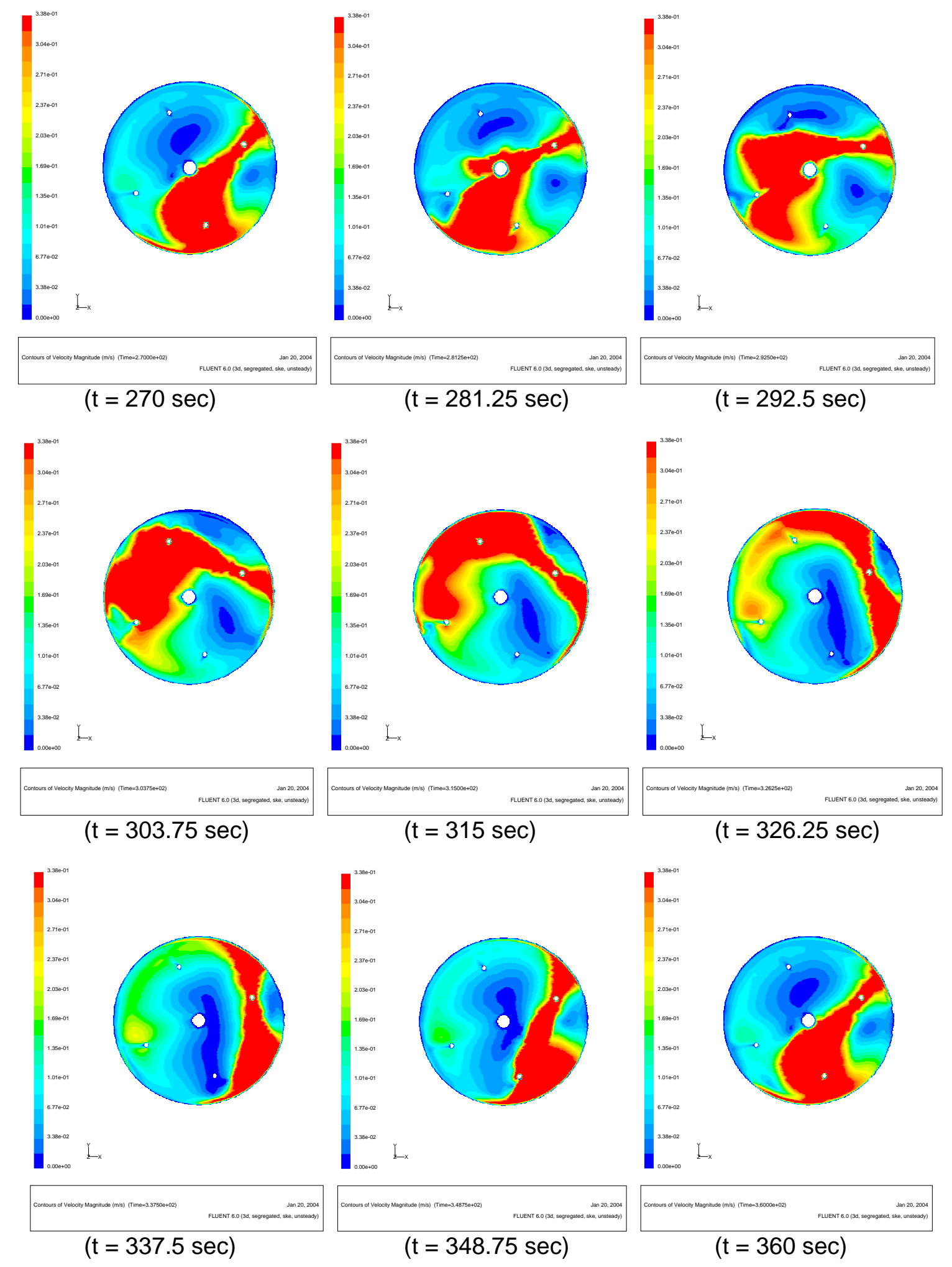

Figure 27. Quasi-steady flow patterns for one pump run with $1 / 3 \mathrm{rpm}$ rotational speed showing that the red zone indicates the suspension zone of 700 micron CST. 

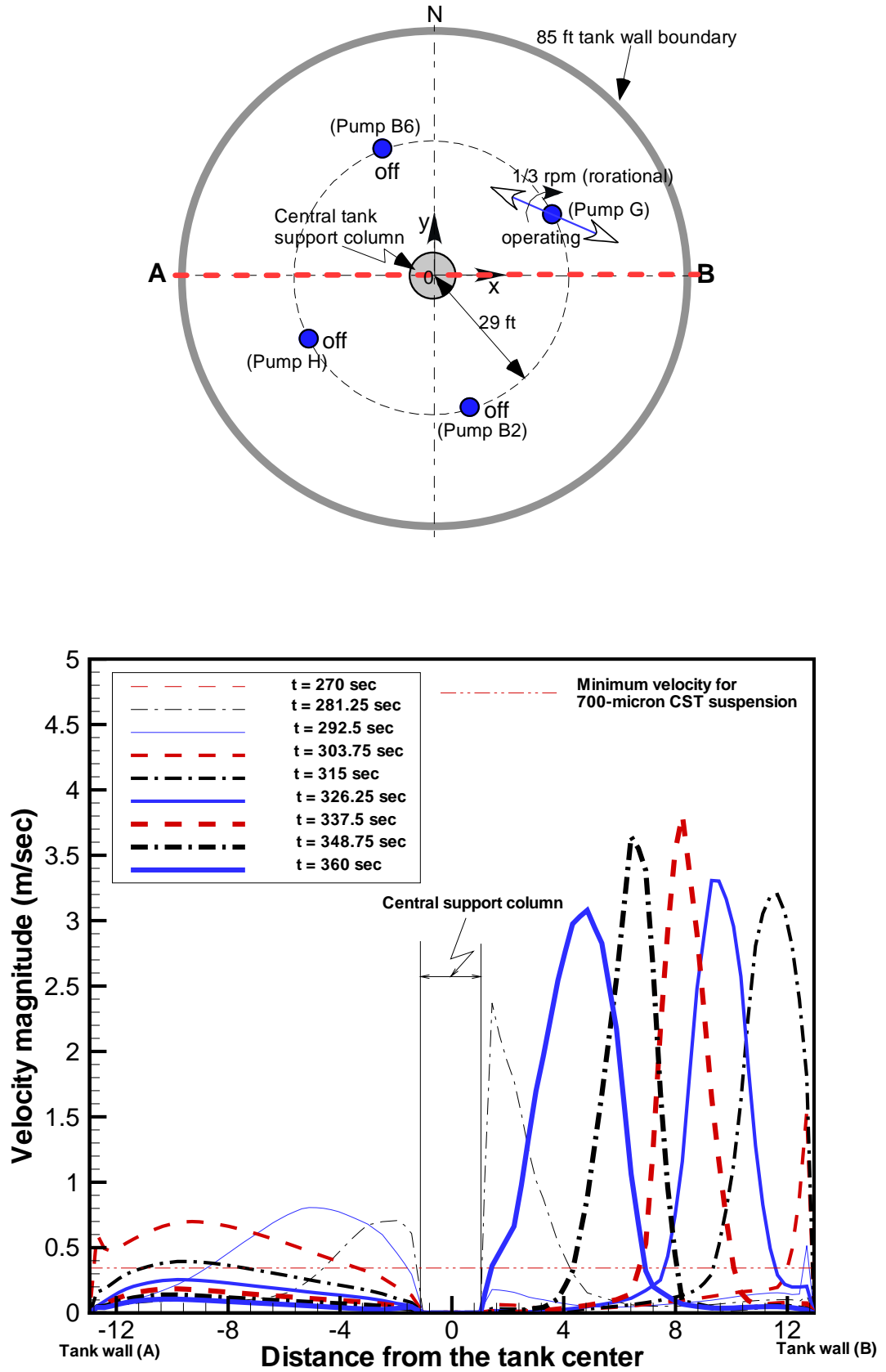

Figure 28. Transient velocity distributions for one pump run with $1 / 3 \mathrm{rpm}$ rotational speed along the centerline A-B crossing the central column of Tank 40 


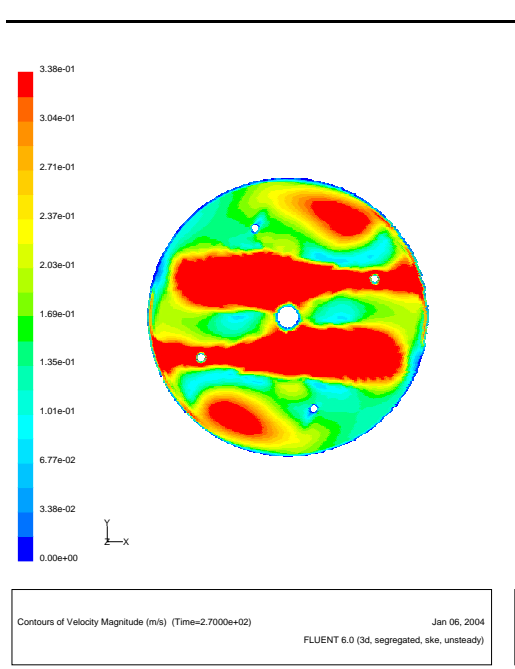

$(\mathrm{t}=270 \mathrm{sec})$

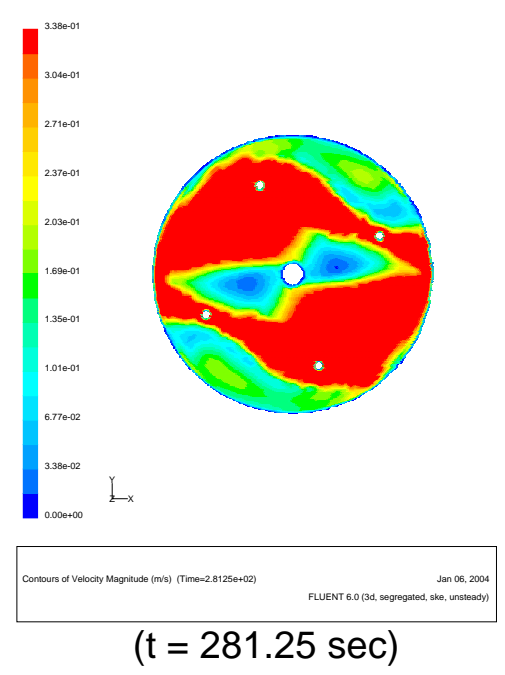

Page:

39 of 48
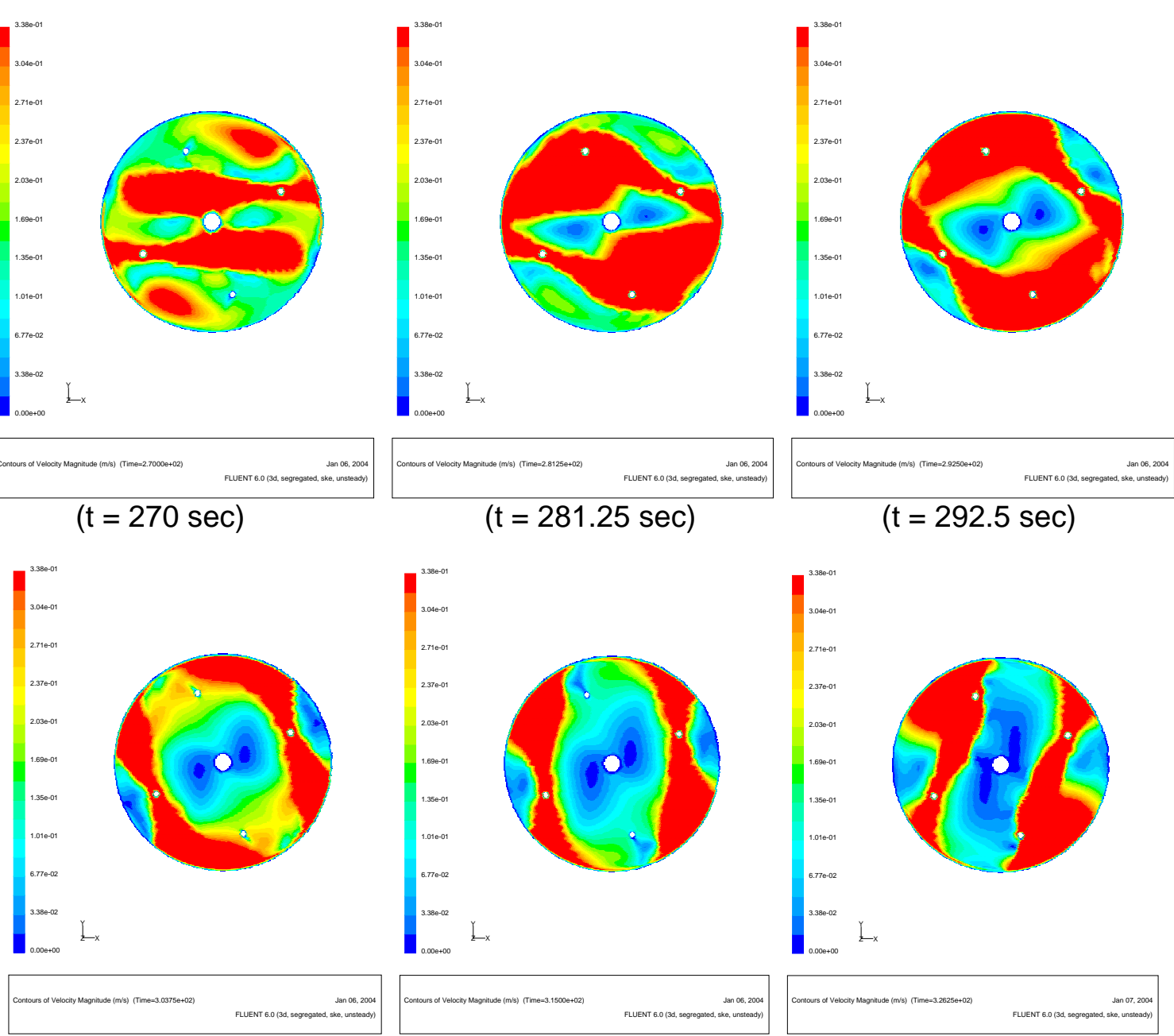

$(t=303.75 \mathrm{sec})$
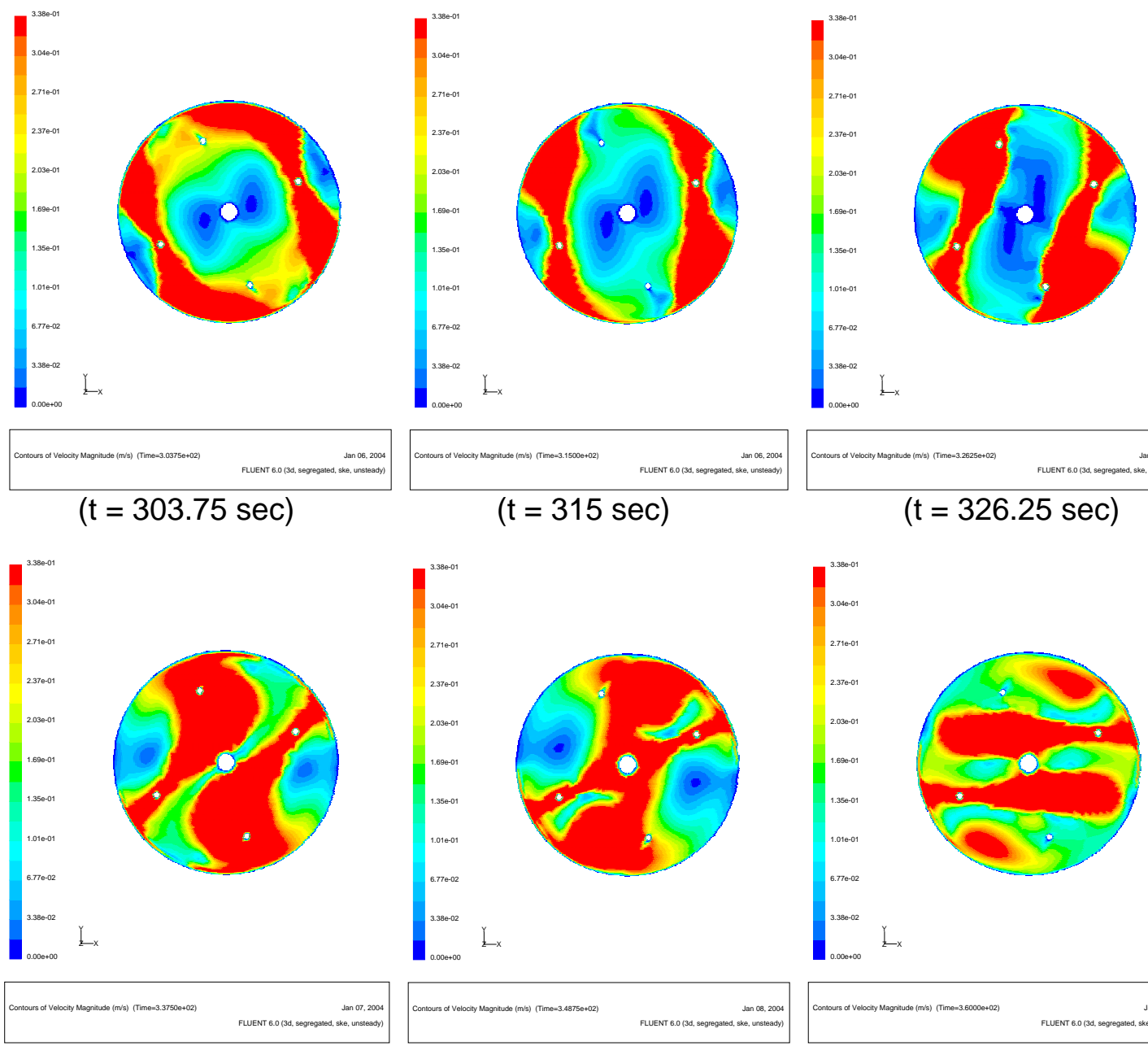

$$
(\mathrm{t}=337.5 \mathrm{sec})
$$
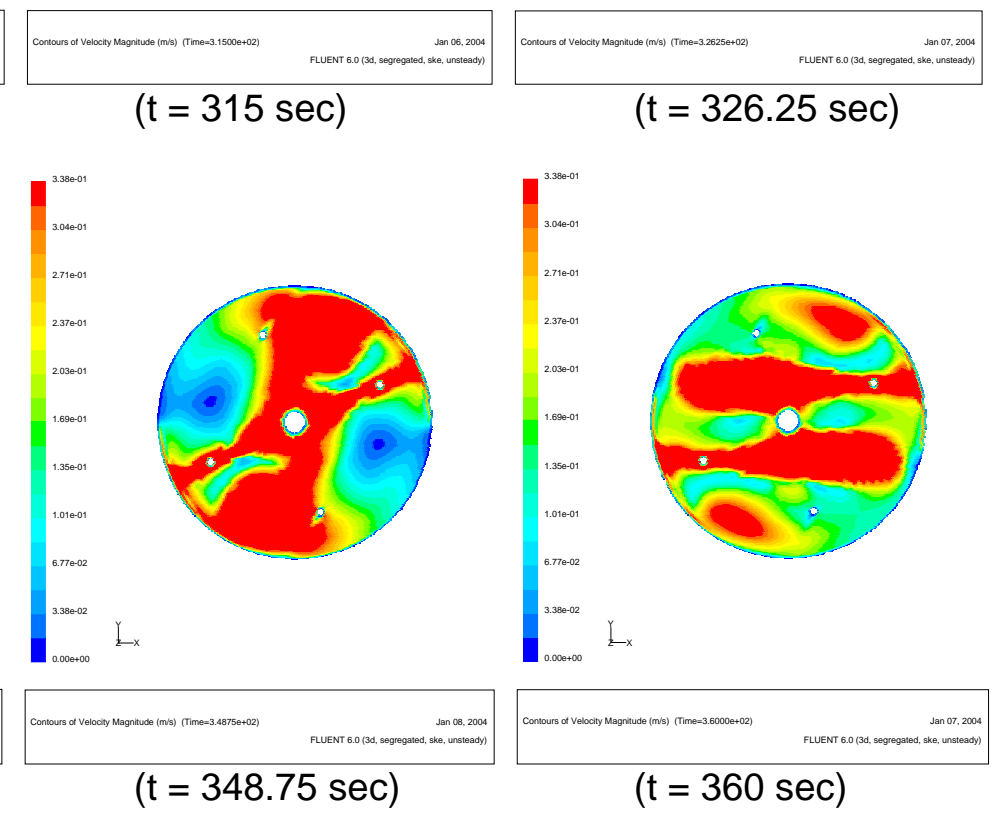

Figure 29. Quasi-steady flow patterns for two pump runs with $1 / 3 \mathrm{rpm}$ rotational speed showing that the red zone indicates the suspension zone of 700 micron CST. 

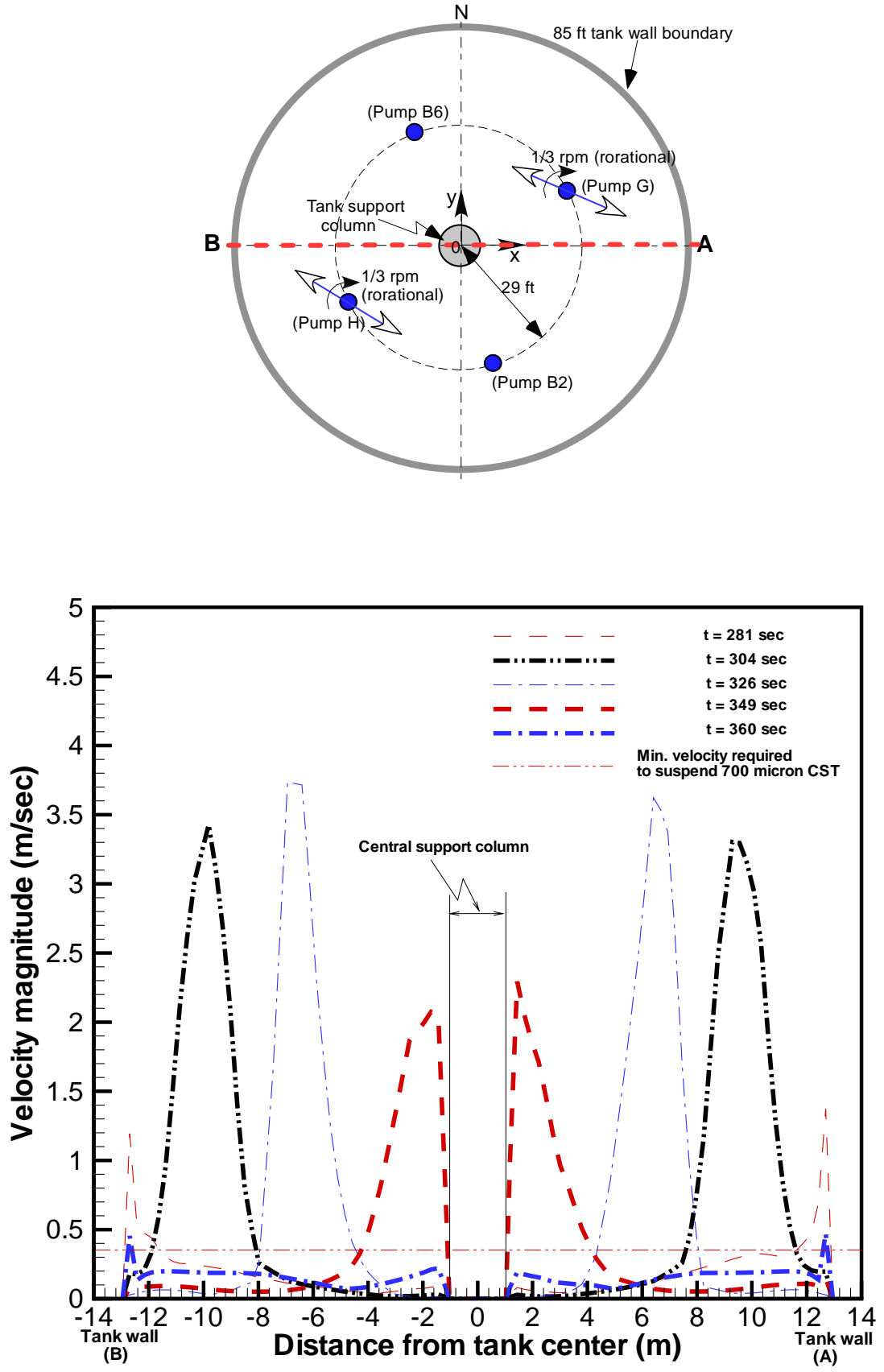

Figure 30. Transient velocity distributions along the centerline line A-B of tank rotational operations of two pumps (pump $\mathrm{G}$ and $\mathrm{H}$ ) 

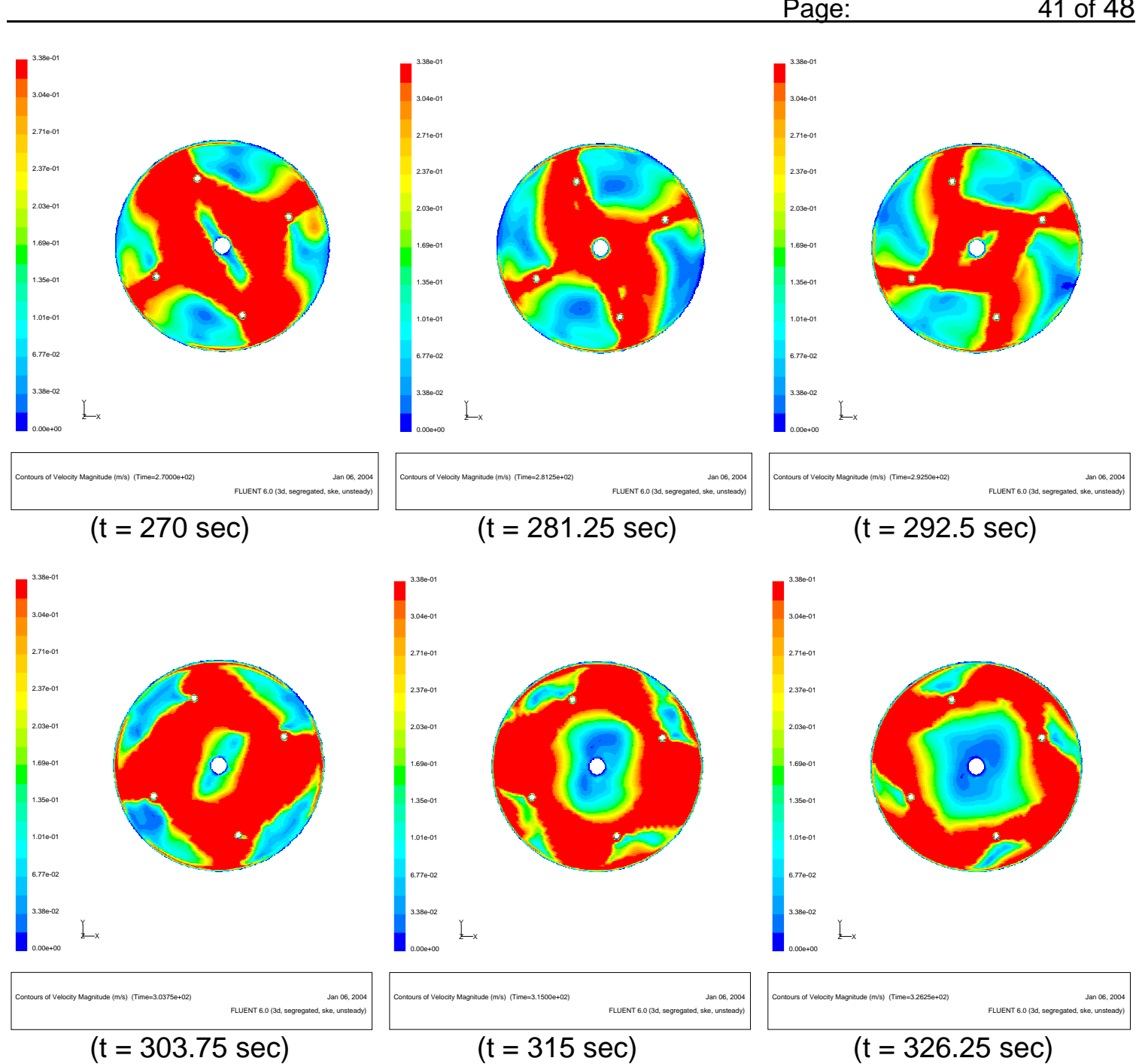

$(t=303.75 \mathrm{sec})$
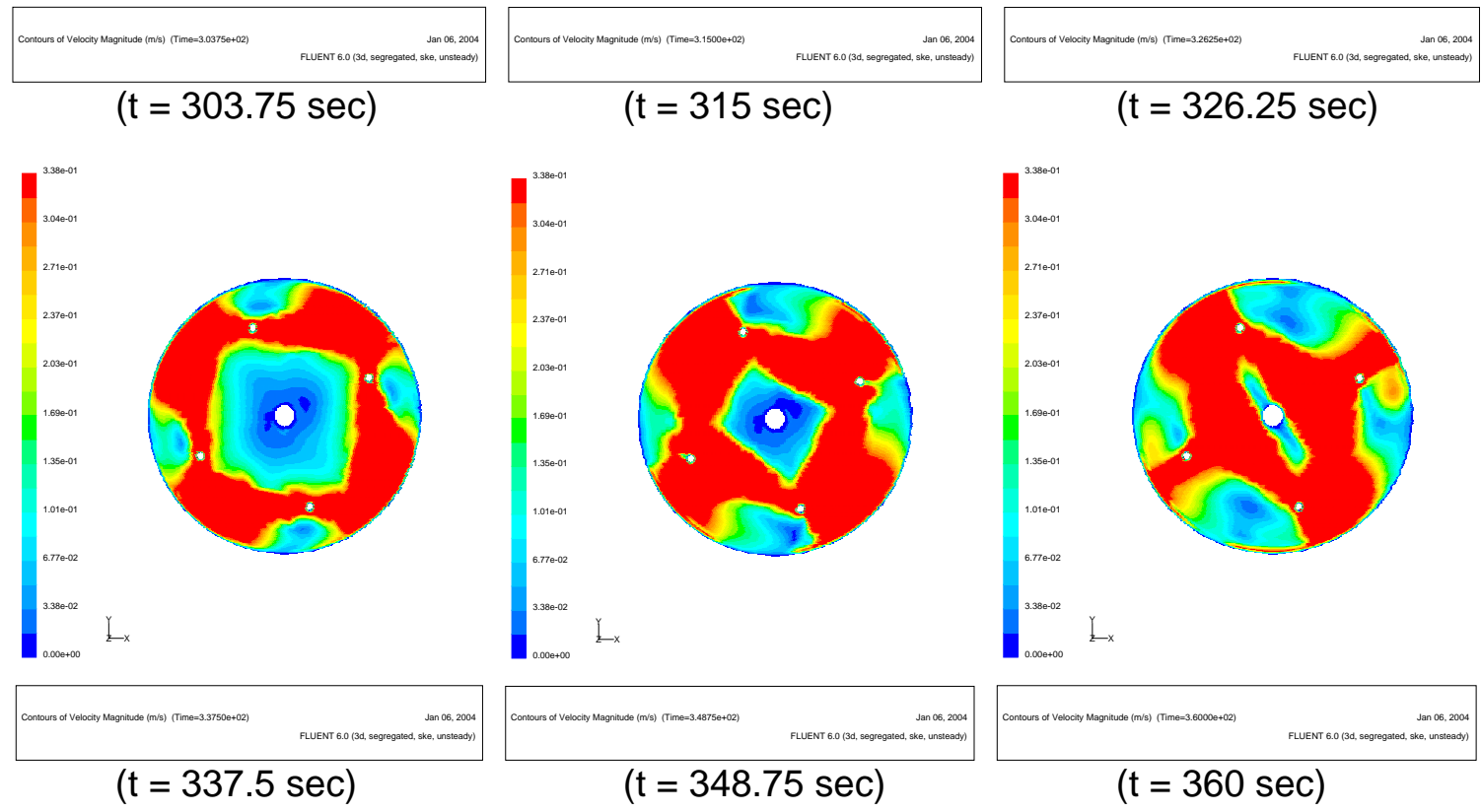

Figure 31. Quasi-steady flow patterns for four pump runs with $1 / 3 \mathrm{rpm}$ rotational speed showing that the red zone indicates the suspension zone of 700 micron CST. 

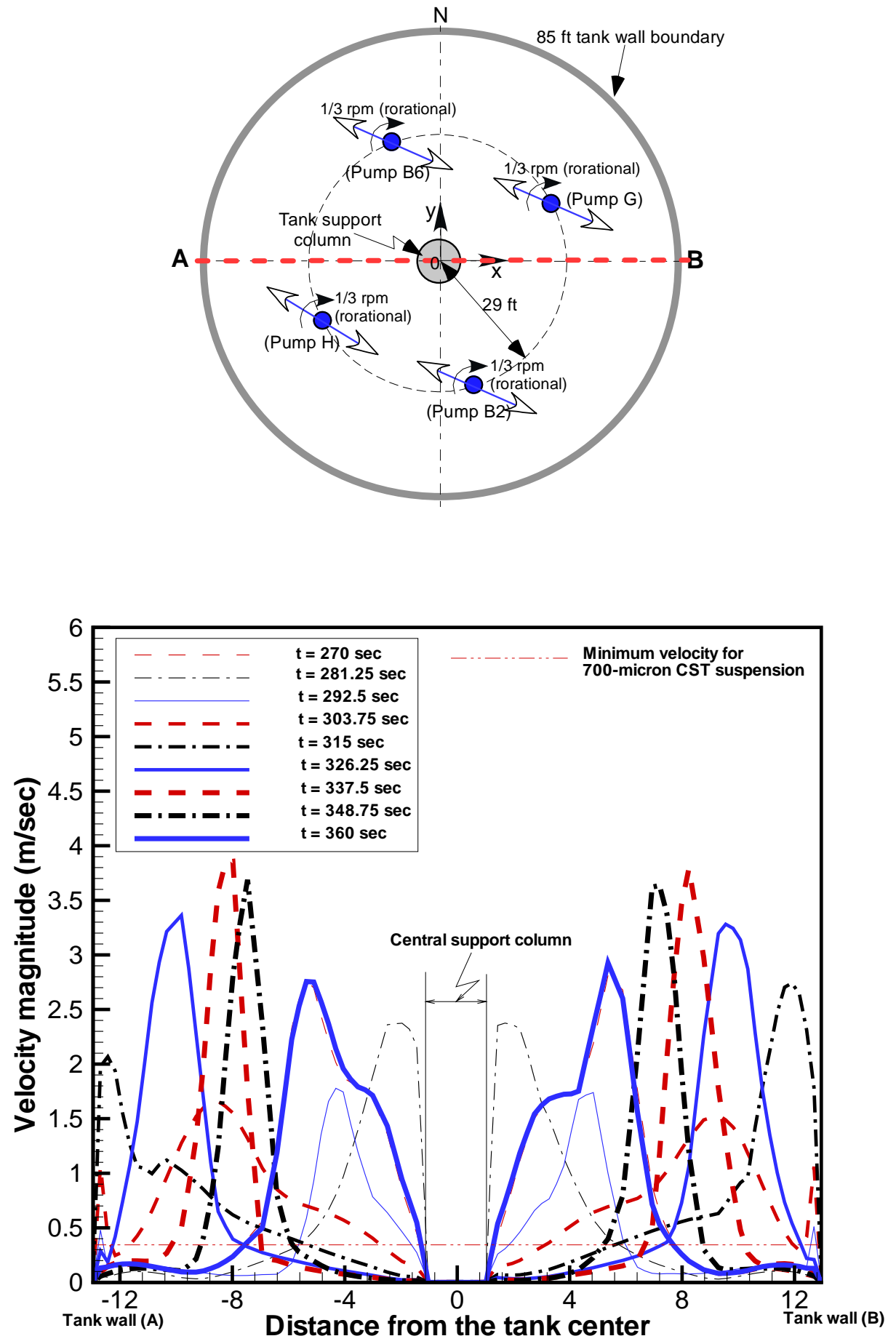

Figure 32. Transient velocity distributions for four pump run with $1 / 3 \mathrm{rpm}$ rotational speed along the centerline A-B crossing the central column of Tank 40 

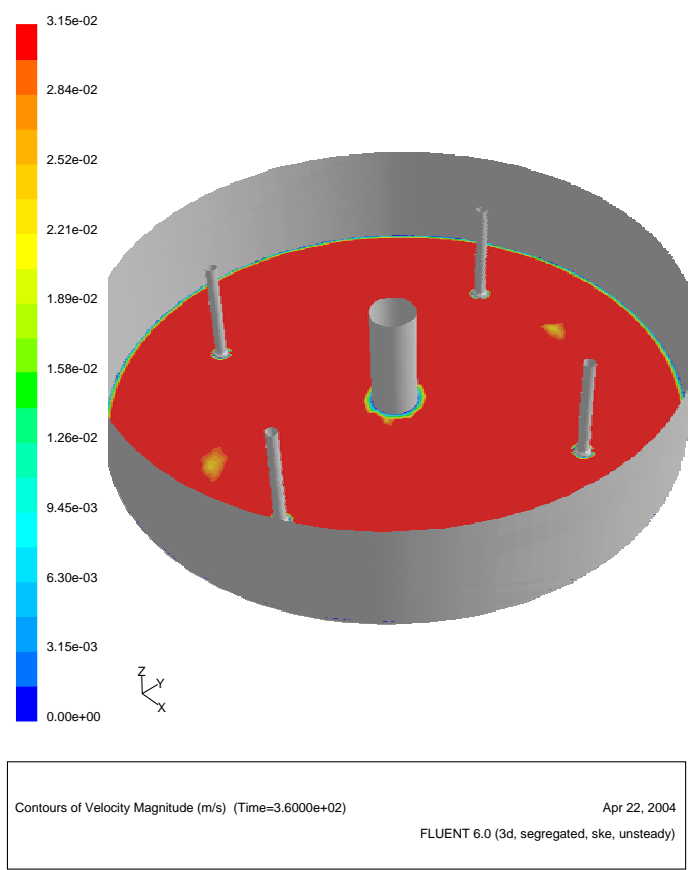

(Velocity contours for nozzle discharge plane under four pump run)

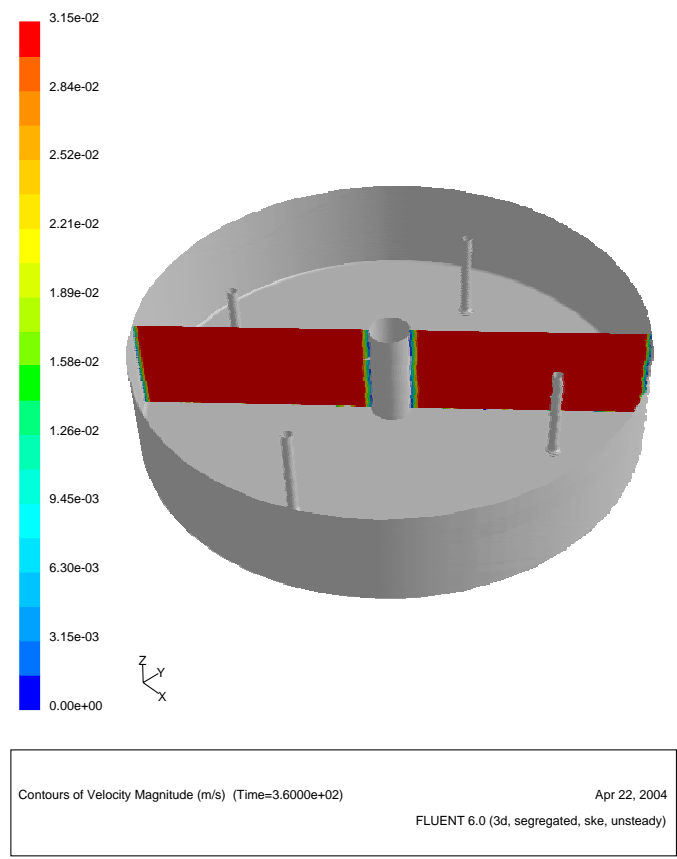

(Vertical central plane crossing the central column under four pump run)

Figure 33. Velocity distributions for four pump run with $1 / 3 \mathrm{rpm}$ rotational speed for the nozzle discharge plane and the vertical central plane crossing the central column of Tank 40 showing that the red zone indicates the suspension zone of 400 micron CST particles 
Report: WSRC-TR-2004-00207

Date: $\quad 6 / 14 / 2004$

Page: $\quad 44$ of 48
WESTINGHOUSE SAVANNAH RIVER COMPANY

CST SUSPENSION ANALYSIS FOR SLURRY PUMPS OF TANK 40

(This Page Intentionally Left Blank) 


\section{Summary and Conclusions}

Tank 40 simulation models with four submersible slurry pumps available for the CST suspension operations have been developed to provide operational guidance of slurry pumps for an efficient sludge removal. A series of the modeling calculations have been performed for key operational parameters such as pump operation mode, number of operating pumps, and to provide a recommendation for CST suspension and mixing operations in Tank 40. Reference design and operating conditions shown in Table 1 were used to perform the modeling analysis of the tank CST mixing. In the analysis, the pump was assumed to be stationary or rotating. Solid obstructions including the pump housing, the 14" riser, and 6.75-ft tank support column were included in the simulation models. Free surface motion of the tank liquid was neglected for high tank liquid level using the literature information.

Steady-state and transient analyses with a two-equation turbulence model were performed with FLUENT ${ }^{\mathrm{TM}}$. All analyses were based on three-dimensional results. A suspension capability was evaluated assuming that local fluid velocity can be used as a measure of CST suspension and mixing. For a minimum suspension velocity of 1.1 $\mathrm{ft} / \mathrm{sec}$ for the largest CST size of 700 microns, the results indicated that at least two existing slurry mixers running at $3800 \mathrm{gpm}$ flowrate per nozzle could keep CST solids suspended from the tank with a 200 in liquid level. In this case, the exception is for the fluid region with less than $20 \mathrm{wt} \%$ contents of CST material. This is based on the conservative assumption that the largest CST size of 700 micron diameter remains unchanged neglecting a friable effect during the entire period of pump operations.

The length of time that the CST material is exposed to the liquid stream lower than minimum suspension velocity is also important in affecting the ability of the liquid stream to suspend CST particle, and this effect is quantified in the present analysis by using the literature results. The model results show that at least two pumps on opposite sides could keep suspending the CST material based on the slurry with $35 \mathrm{wt} \%$ contents, but that at lower concentrations, particles larger than about 400 microns would tend to settle quickly and probably not remain in suspension long enough for the opposite jet to come around and stir that region of the tank.

The main conclusions are as follows:

- The steady-state flow patterns on the horizontal discharge plane follow a series of parabolic curves similar to that of a free jet available in the literature.

- For the simulations, a series of the modeling calculations was performed with indexed stationary and rotating pump operations. The calculated results demonstrated that the existing slurry pumps running at $7600 \mathrm{gpm}$ could suspend the CST particles from the tank with a 200 in liquid level, based on a minimum sludge suspension velocity of about $1.1 \mathrm{ft} / \mathrm{sec}$ for 700 micron CST particle.

- The suspension distance for the transient model with pump rotations is smaller than that of the steady-state model with indexed pump orientations for given operating conditions. However, total suspension extents for the two modeling cases have about the same area. 
Page: $\quad 46$ of 48

- The modeling results demonstrate that pump rotations provide more uniform flow circulation patterns with respect to the indexed pump operations, leading to larger suspension capabilities of CST particles.

- It is emphasized that the more pump operations and the higher pump rotating speed are more efficient in terms of CST suspension capability since allowable settling time during the pump operations becomes smaller.

The analysis results performed by the present models will be used to evaluate hydraulic suspension capabilities for CST mixing. This information will also assist in the operating plan for the Tank 40 CST suspension and in identifying special operation requirements for the suspension and mixing of the tank. 


\section{References}

1. C. I. Aponte, "Modeling Input for Slurry Pump Information" e-mail, October 1, 2003.

2. Drawing for Additional Waste Storage Tanks Top Slab Plan - Tank 40 Concrete and Steel, Dwg. No. W700759 Rev. 44.

3. D. T. Bostick and W. V. Steele, "Thermal and Physical Property Determinations for IonsivR IE0-911 Crstalline Silicotitanate and Savannah River Site Waste Simulant Solutions", ORNL/TM-1999/133, August 1999.

4. D. R. Oliver, "The Sedimentation of Suspensions of Closely-Sized Spherical Particles", Chemical Engineering Science, Vol. 15, pp. 230-242, 1961.

5. E. J. Freed and P. S. Mukherjee, "Tank 8 Waste Removal Operating Plan", U-ESRF-00009, Rev. 5, April 2001.

6. S. Y. Lee and R. A. Dimenna, "Heel Removal Analysis for Mixing Pumps of Tank 8", WSRC-TR-2002-00460 (September 2002).

7. S. Y. Lee and R. A. Dimenna, "Performance analysis for Mixing Pumps in Tank 18", WSRC-TR-2001-00391 (October 2001).

8. N. V. Chadrasekhara Swamy and P. Bandyopadhyay, "Mean and Turbulence Characteristics of Three-Dimensional Wall Jets", Journal of Fluid Mechanics, Vol. 71, Part 3, pp. 541-562 (1975).

9. FLUENT, Fluent, Inc. (1998).

10. S. Y. Lee, "Evaluation of Sludge Removal Capabilities for ADMP Mixer in Tank 18, WSRC-TR-2003-00166, April 2003.

11. J. M. Dallavalle, Micromeritics, $2^{\text {nd }}$ Edition, Pitman Publishing Corporation, New York (1948).

12. C. K. Madina and L. P. Bernal of F, "Interaction of a Turbulent Round Jet with the Free surface", Journal of Fluid Mechanics, Vol. 261, pp. 305-332 (1994)

13. Abramovich, G. N., "The Theory of Turbulent Jets", The MIT Press, Cambridge, MA, 1963.

14. H. Schlichting, Boundary Layer Theory, McGraw-Hill Book Company, New York (1967).

15. G. Tatterson, "Sludge Suspension in Waste Storage Tanks", DPST-89-257, January 6, 1989.

16. Graf, W. H., Hydraulics of Sediment Transport, McGraw-Hill Book Company, New York, 1971.

17. H. Tennekes and J. L. Lumley, A First Course in Turbulence, The MIT Press, Cambridge, MA, 1972. 
Report: WSRC-TR-2004-00207

Date: $\quad 6 / 14 / 2004$

Page: $\quad 48$ of 48
WESTINGHOUSE SAVANNAH RIVER COMPANY

CST SUSPENSION ANALYSIS FOR SLURRY PUMPS OF TANK 40

(This Page Intentionally Left Blank) 